\title{
The scientific basis for a satellite mission to retrieve CCN concentrations and their impacts on convective clouds
}

\author{
D. Rosenfeld ${ }^{1}$, E. Williams ${ }^{2}$, M. O. Andreae ${ }^{3}$, E. Freud ${ }^{1}$, U. Pöschl ${ }^{3}$, and N. O. Rennó ${ }^{4}$ \\ ${ }^{1}$ Institute of Earth Sciences, The Hebrew University of Jerusalem, Jerusalem 91904, Israel \\ ${ }^{2}$ Parsons Laboratory, Massachusetts Institute of Technology (MIT), 77 Massachusetts Avenue, Cambridge, MA, 02139, USA \\ ${ }^{3}$ Biogeochemistry Department, Max Planck Institute for Chemistry, P.O. Box 3060, 55020 Mainz, Germany \\ ${ }^{4}$ Department of Atmospheric, Oceanic and Space Sciences, University of Michigan, 1531C Space Research Building, 2455 \\ Hayward St., Ann Arbor, \\ MI 48109, USA
}

Correspondence to: D. Rosenfeld (daniel.rosenfeld@huji.ac.il)

Received: 25 January 2012 - Published in Atmos. Meas. Tech. Discuss.: 10 February 2012

Revised: 21 July 2012 - Accepted: 25 July 2012 - Published: 23 August 2012

\begin{abstract}
The cloud-mediated aerosol radiative forcing is widely recognized as the main source of uncertainty in our knowledge of the anthropogenic forcing on climate. The current challenges for improving our understanding are (1) global measurements of cloud condensation nuclei $(\mathrm{CCN})$ in the cloudy boundary layer from space, and (2) disentangling the effects of aerosols from the thermodynamic and meteorological effects on the clouds. Here, we present a new conceptual framework to help us overcome these two challenges, using relatively simple passive satellite measurements in the visible and infared (IR). The idea is to use the clouds themselves as natural CCN chambers by retrieving simultaneously the number of activated aerosols at cloud base, $N_{\mathrm{a}}$, and the cloud base updraft speed. The $N_{\mathrm{a}}$ is obtained by analyzing the distribution of cloud drop effective radius in convective elements as a function of distance above cloud base. The cloud base updraft velocities are estimated by double stereoscopic viewing and tracking of the evolution of cloud surface features just above cloud base. In order to resolve the vertical dimension of the clouds, the field of view will be $100 \mathrm{~m}$ for the microphysical retrievals, and $50 \mathrm{~m}$ for the stereoscopic measurements. The viewing geometry will be eastward and 30 degrees off nadir, with the Sun in the back at 30 degrees off zenith westward, requiring a Sun-synchronous orbit at 14 LST. Measuring simultaneously the thermodynamic environment, the vertical motions of the clouds, their microstructure and the $\mathrm{CCN}$ concentration will allow separating the dynamics from the CCN effects. This concept is being applied in
\end{abstract}

the proposed satellite mission named Clouds, Hazards and Aerosols Survey for Earth Researchers (CHASER).

\section{Introduction}

\subsection{Uncertainty in aerosol cloud-mediated forcing drives the climate uncertainty}

The effects of aerosols on clouds are recognized by the IPCC (2007) as the largest sources of uncertainty in the quantification of anthropogenic perturbations to the Earth's energy balance. Therefore, the reduction of this uncertainty is necessary for improving our understanding of the present climate and for the reduction of the uncertainties in the prediction of future climates (e.g., Andreae et al., 2005; Kiehl, 2007). The uncertainty in aerosol cloud-mediated radiative forcing is composed of two possibly large and highly uncertain opposite effects from shallow and deep clouds (Rosenfeld et al., 2012a). This underlines the importance of conducting global measurements of the aerosol effects on clouds. This paper introduces a new concept for retrieving from space microphysical and dynamical properties of convective clouds and reconstructs from that the cloud condensation nuclei $(\mathrm{CCN})$, the vertical motions of the cloud tops, and the height at which rain and cloud glaciations initiate. This will allow disentangling the effects of aerosols (CCN and ice nuclei) and meteorology (cloud vertical motion, temperatures and depth) on 
the properties of the observed cloud and precipitation properties. A satellite mission for measuring the cloud properties is described in Renno et al. (2012). The full characterization of the cloud-aerosol-precipitation interactions can be achieved when combined with precipitation properties observed by other satellites or ground based measurements. Here, we provide the scientific basis for these kinds of measurements from space, showing the feasibility of what has been considered impossible until now.

On a more technical level, this study focuses on the way by which combining a large number of various satelliteretrieved properties can provide new fundamentally important retrieved entities, while doing it on a sufficiently high resolution that can resolve the smallest convective elements. Characterization of the exact performance of retrieving each of the input-retrieved parameters constitutes a major study in its own right, which requires simulation and validation at the relevant scales. This pertains to properties such as cloud surface temperature, cloud particle effective radius, cloud phase, precipitable water above the cloud top, cloud surface vertical motion, and relation between cloud top rising rate and cloud updraft. This exact characterization has not yet been achieved. The realization of the kind of benefits that can be realized when these parameters are combined in the framework presented here will hopefully serve as a motivation for the additional studies required for the exact characterization. For error calculations of these properties and for calculating the error propagation through the high level products, we will use references where available or some estimates based on theoretical considerations.

\subsection{Ways by which aerosols affect cloud microphysical, precipitation and radiation properties}

Aerosols are extremely important to cloud radiative forcing because cloud droplets are nucleated on pre-existing aerosols that serve as cloud condensation nuclei (CCN) and ice nuclei. The cloud droplet concentrations, $N_{\mathrm{d}}$, that form near cloud base depend on the supersaturation $(S)$ activation spectrum, $\mathrm{CCN}(S)$, and on the cloud base updraft speed, $w_{\mathrm{b}}$. The CCN that actually nucleate cloud droplets in specific clouds are referred to as activated $\mathrm{CCN}$, and their number density before dilution by mixing with ambient non-cloudy air is denoted as $N_{\mathrm{a}}$. The mixing with ambient air reduces $N_{\mathrm{a}}$ to $N_{\mathrm{d}}$, as long as no new droplets are nucleated. Such new nucleation can occur well above cloud base when cloud droplets are depleted by conversion into precipitation and the supersaturation increases (Pinsky and Khain, 2002). This is rarely an issue in non-precipitating boundary layer clouds. This number determines the variability of the fundamental properties of the clouds in a given meteorological situation. The albedo of clouds with a given value of vertically-integrated liquid water path increases with $N_{\mathrm{d}}$ (Twomey, 1977). With greater $N_{\mathrm{d}}$ smaller droplets are formed, reducing coalescence and inhibiting rain production (Gunn and Phillips, 1957; Squires,
1958). The dynamic response to the rain suppression lengthens the life-time and increases the cloud cover when suppressing precipitation in clouds, at least in the case of shallow heavily drizzling marine stratocumulus (Albrecht, 1989; Rosenfeld et al., 2006; Lebsock et al., 2008; Wang et al., 2011; Goren and Rosenfeld, 2012). In contrast, adding CCN to non-precipitating clouds can enhance their evaporation and mixing with the ambient air due to the decrease in cloud drop size (e.g., Wood, 2007; Jiang et al., 2009; Chen et al., 2011). In deep convective clouds rain forms eventually, but the aerosol-induced delay in its formation to greater heights was shown to cause in some conditions cloud invigoration (Andreae et al., 2004; Rosenfeld et al., 2008a; Fan et al., 2012) and additional electrification (Yuan et al., 2011). The invigoration was shown to occur mainly for situations with weak wind shear and for clouds with warm base, in which there is large vertical distance between cloud base and the freezing level (Fan et al., 2009; Li et al., 2011). The aerosolinduced vertical growth and the consequent expansion of the anvils into cirrus was observed (Koren et al., 2010) and simulated (Fan et al., 2012) to inflict large positive radiative forcing, in contrast to the strong negative forcing that is caused by the aerosol effect on shallow clouds, at least in heavily drizzling marine stratocumulus (e.g., Albrecht, 1989). In the context of tropical cyclones, the invigoration of clouds at the periphery of the storms occurs at the expense of a reduction in the amount of air converging into the storm center, hence reducing the maximum wind speeds (Rosenfeld et al., $2012 \mathrm{~b}$ and references therein). The aerosols were found even to affect the potential of deep convective clouds to produce large hail and tornadoes, where clouds with added pollution aerosols become potentially more damaging (Rosenfeld and Bell, 2011 and references therein). The impact of aerosols on cloud invigoration and the vertical distribution of latent heating can also modulate regional and large scale circulation systems, as observed by Bell et al. (2008) and simulated by Fan et al. (2012).

\subsection{Uncertainties in global measurements of cloud-mediated radiative forcing by aerosols}

Based on this brief summary of aerosol effects on clouds, it is evident that having accurate measurements of $\mathrm{CCN}$ activation spectra as a function of water vapor supersaturation - $\mathrm{CCN}(S)$ - is vital for a quantitative understanding of the weather systems and the aerosol impacts on the Earth energy budget and climate. This information is a necessary component for disentangling the effects of aerosols from those of the greenhouse gases on the Earth energy budget, and hence for understanding climate change and for climate prediction.

Global measurements are practical only from space. Aerosol properties such as aerosol optical depth have been measured from space, but the interpretation of the measurable quantities into $\operatorname{CCN}(S)$ is still challenging. The radiative forcing caused by impacts of aerosol on clouds is inferred 
from satellite observations where aerosol optical properties are compared to cloud radiative properties. This practice is inaccurate, mainly because of the poor ability to convert the aerosol optical depth (AOD) into concentrations of cloud condensation nuclei $(\mathrm{CCN})$ that actually interact with the clouds (Andreae, 2009). The inaccuracies are caused by the fact that aerosols are not measured at the same height as the cloud base, cloud contamination (i.e., clouds enhancing the aerosol signals), and aerosol swelling in the moist environment near the clouds (Koren et al., 2007). Furthermore, aerosols in the cloudy boundary layers are often obscured by the clouds so that there is no way to measure them directly regardless of these issues with accuracy. This obviously occurs in conditions where the importance for measuring them is greatest because they interact with the clouds that obscure or distort their satellite view. Inaccuracies in the cloud properties are caused by mixing clouds that feed from the boundary layer with clouds that have elevated bases above the boundary layer, and hence are not interacting with the aerosols there. Another yet unresolved challenge is correct retrieval of the properties of ensembles of convective clouds. A serious limitation is the inability of the aerosols and clouds in conditions of high fractional cloud coverage to be retrieved simulataneously. As a result, the practice of relating retrieved cloud to retrieved aerosol properties is plagued by large errors in both parameters, which may cause both random errors and systematic biases. Mathematically, adding random noise to two physically linearly related variables (e.g., $Y=a X$ ) causes the correlation to decrease and the slope to tend toward zero. Therefore, the large observational errors in the dependence of clouds on aerosol properties have likely caused an underestimate of the slopes of their relationships, which is defined to be the observed aerosol indirect effect (AIE). This error might explain the low estimates of the observed AIE as compared to results of model simulations (e.g., Quass et al., 2009; Penner et al., 2011).

\section{A new proposed concept for measuring aerosol indirect effect}

This paper introduces a new concept for measuring simultaneously $\mathrm{CCN}(S)$ and the microphysical and dynamical properties of the clouds for assessing quantitatively the cloudinteractions with global coverage from satellites. A proposed satellite mission named "Clouds, Hazards, and Aerosols Survey for Earth Researchers" (CHASER) is based on this concept (Renno et al., 2012). The satellite has two main instruments: the Multi-Spectral Imager (MSI) that will have a field of view of $100 \mathrm{~m}$ by $102.4 \mathrm{~km}$ at the center of the ground track for all wavelengths. The satellite view will point $30^{\circ}$ off nadir eastward, with the Sun at $30^{\circ}$ off zenith on the west, at a local solar time of 14 LST. The MSI will have 12 spectral bands in the visible, near infared (IR) and thermal IR, as shown in Table 1.
Table 1. The spectral bands of the Multi-Spectral Imager, which will have a footprint of $100 \mathrm{~m}$.

\begin{tabular}{lll}
\hline Wave band & Channel name & $\mathrm{SNR}^{\mathrm{a}}$ or NEDT \\
\hline $450-470 \mathrm{~nm}$ & Blue & $\mathrm{SNR}=4$ \\
$560-580 \mathrm{~nm}$ & Green & $\mathrm{SNR}=4$ \\
$670-690 \mathrm{~nm}$ & Red & $\mathrm{SNR}=4$ \\
$1070-1200 \mathrm{~nm}$ & Vapor wide & $\mathrm{SNR}=5$ \\
$1120-1150 \mathrm{~nm}$ & Vapor narrow & $\mathrm{SNR}=5$ \\
$1365-1395 \mathrm{~nm}$ & Cirrus absorption & $\mathrm{SNR}=2$ \\
$2080-2150 \mathrm{~nm}$ & 2.1 Phase water & $\mathrm{SNR}=2$ \\
$2200-2310 \mathrm{~nm}$ & 2.3 Phase ice & $\mathrm{SNR}=2$ \\
$3420-3950 \mathrm{~nm}$ & 3.7 Effective radius & $\mathrm{SNR}=5 ; \mathrm{NEDT}=0.2 \mathrm{~K}$ at $246 \mathrm{~K}$ \\
$8.3-9.25 \mu \mathrm{m}$ & 8.7 Temperature & $\mathrm{NEdT}=0.1 \mathrm{~K}$ at $232 \mathrm{~K}$ \\
$10.2-11.2 \mu \mathrm{m}$ & 10.7 Temperature & $\mathrm{NEdT}=0.1 \mathrm{~K}$ at $270 \mathrm{~K}$ \\
$11.2-12.3 \mu \mathrm{m}$ & 11.7 Temperature & $\mathrm{NEdT}=0.2 \mathrm{~K}$ at $300 \mathrm{~K}$ \\
\hline
\end{tabular}

a SNR, signal-to-noise ratio. Required SNR values calculated for $1 \%$ albedo and $30^{\circ}$ solar and viewing angles.

b NEDT, noise equivalent differential temperature.

Cloud vertical motions will be obtained by using a sequence of stereoscopic images that map the evolution of the cloud surface. The Multi Angle Imager (MAI) onboard CHASER has this capability. The MAI consists of three visible high resolution cameras. The center camera points $30^{\circ}$ off nadir eastward. The other two cameras point $30^{\circ}$ off nadir across-track (eastward) and $\pm 30^{\circ}$ off nadir along-track to achieve a stereo geometry with the Sun at the back as illustrated in Fig. 1. The field of view of each camera is $50 \mathrm{~m}$ by $102.4 \mathrm{~km}$, with a spatial resolution of $50 \mathrm{~m}$ at their ground center track. The three cameras cross scan the same ground track, providing a sequence of three images 1 minute apart, from three different viewing angles. The idea of vertical microphysical profiling from space was introduced by Rosenfeld and Lensky (1998), using the Advanced Very High Resolution Radiometer (AVHRR) observing the temperature and particle effective radius $\left(r_{\mathrm{e}}\right)$ at the tops of convective clouds at various stages of vertical development. This idea was improved to a proposed side scanning satellite (Martins et al., 2011), and further developed by enhancing the resolution and with the addition of the MAI for CHASER (Renno et al., 2012).

Traditionally, CCN are measured in laboratory or field experiments with a cloud chamber where known water vapor supersaturation $(S)$ is applied to an air sample and the activated cloud droplets are counted. Here, we view clouds as natural cloud chambers where the number of nucleated aerosols in cloud droplets, $N_{\mathrm{a}}$, and $S$ can be retrieved, and hence the CCN spectrum can be obtained. Specifically, the approach uses the retrieved $N_{\mathrm{a}}$ from the dependence of the cloud drop size on the potential amount of condensed cloud water as a function of distance above cloud base, along with retrieved updrafts near cloud base, $w_{\mathrm{b}}$, for calculating the $\mathrm{CCN}$ activation spectra as a function of $S$. This information is used to map CCN in the cloudy boundary layer globally. This is important because this maps $\mathrm{CCN}$ and $w_{\mathrm{b}}$, the fundamental 


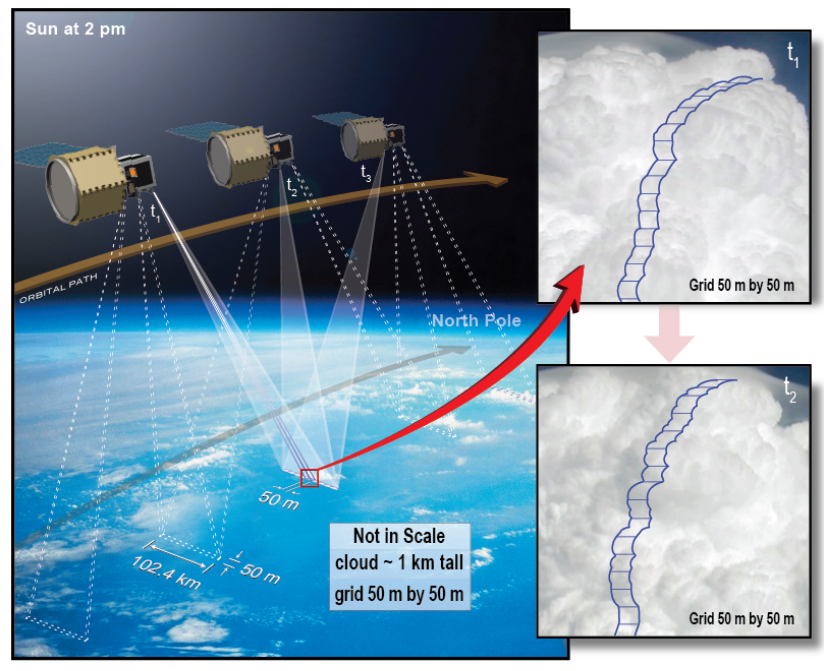

Fig. 1. An illustration of the measured vertical profiles of cloud parameters pointing $30^{\circ}$ off track toward sun-illuminated cloud surfaces.

physical entities determining $N_{\mathrm{a}}$, which in turn determine the remaining cloud properties (e.g., cloud drop effective radius and initiation of rain as a function of height above base). Retrieving $N_{\mathrm{a}}$ and cloud base updraft velocities is required for disentangling the impacts of dynamics from microphysics on the various cloud properties.

The concept of using ground-based cloud observations for retrieving $\mathrm{CCN}$ was originally proposed by Feingold et al. (1998). They retrieved CCN using measurements of $w_{\mathrm{b}}$ with vertically pointing Doppler cloud radar, and $N_{\mathrm{d}}$ estimated from a combination of cloud radar and passive microwave measurements. Obtaining the size distribution of the aerosols by lidar or other measurements can provide the $\mathrm{CCN}$ supersaturation activation spectrum. This method was applied to ground-based measurements of marine stratocumulus clouds at Point Reyes, California, to obtain the aerosol effects on cloud radiative forcing (McCominsky and Feingold, 2011). They showed that the variability in liquid water path (LWP) that occurs due to 3-D effects and cloud mixing tends to reduce the measured strength of the albedo effect.

The proposed methodology represents a significant advancement, as it can use satellite measurements and therefore provide global coverage for retrieved $\mathrm{CCN}$ and cloud properties. Furthermore, variability in LWP for a cloud with a given depth and $N_{\mathrm{d}}$ is not a source of error for this methodology.

\section{$3 \quad \mathrm{~N}_{\mathrm{a}}$ as a fundamental extensive cloud property}

In this section we show that the number of activated aerosols at cloud base, $N_{\mathrm{a}}$, is a fundamental property that determines to a large extent the microstructure of the cloud as a whole. $N_{\mathrm{a}}$ is determined by the aerosol size distribution, chemical composition, and water vapor supersaturation at cloud base.
The latter is determined by $\mathrm{CCN}(S)$ and the updraft speed at cloud base. In a hypothetical cloud parcel rising adiabatically, the diameters of the cloud droplets grow in proportion to the cube root of the adiabatic cloud liquid water content [mixing ratio], $q_{\mathrm{La}}$. This occurs because $q_{\mathrm{La}}=4 / 3 \rho_{\mathrm{L}} \pi r_{\mathrm{v}}^{3} N_{\mathrm{a}}$, where $r_{\mathrm{v}}$ is the mean cloud droplet volume radius, and $\rho_{\mathrm{L}}$ is the water density. $N_{\mathrm{a}}$ can be readily calculated because $q_{\mathrm{La}}$ is a known thermodynamic function of the cloud depth, $D$ (the vertical distance above cloud base). Real clouds are far from being adiabatic, of course, but fortunately the mixing and dilution of convective clouds occurs in a way that leaves the $r_{\mathrm{v}}$ as if the clouds were nearly adiabatic. This occurs because clouds mix nearly inhomogeneously (e.g., Paluch and Baumgardner, 1989). That is, cloud droplets directly exposed to mixing evaporate completely leaving the remaining droplets unaffected. This leads to a reduction of $N_{\mathrm{d}}$ and of the cloud water content, $q_{\mathrm{L}}$, but mixing does not affect $r_{\mathrm{v}}$. Burnet and Brenguier (2007), based on aircraft measurements with a sampling rate of $10 \mathrm{~Hz}$ (providing 10-m resolution in cloud), reported a state that is more intermediate between the two extreme mixing states, whereas Paluch and Baumgardner (1989) and Freud et al. (2011) using a sampling rate of $1 \mathrm{~Hz}$, or a scale of 100 path length in clouds. According to Lehmann et al. (2009) mixing is expected to become more homogeneous at smaller scales. This apparent disagreement can be resolved when realizing that mixing goes to the homogeneous at the very small scales $(<10 \mathrm{~m})$. Taking it to the limit, at the scale of the single droplet the mixing by definition is homogeneous, as the droplet must evaporate gradually and not vanish instantaneously when exposed to dry air. When observing larger volumes, the time or space scale at which the droplets evaporate becomes smaller with respect to the observation scale. At the extreme, there is a clear demarcation between cloud and cloud free air, as water clouds do not diffuse gradually into their environment as smoke or cirrus clouds do. The satellite views the clouds at the $100 \mathrm{~m}$ scale, which is similar to the aircraft measurement scale at $1 \mathrm{~Hz}$ being $\sim 100 \mathrm{~m}$ flight path. Therefore, the $100 \mathrm{~m}$ scale is the relevant one for the application to CHASER.

Examples from aircraft measurements (from Freud et al., 2011) are shown in Figs. 2-4. Another fortunate fact is the highly repeatable tight linear relationship between $r_{\mathrm{v}}$ and cloud droplet effective radius, $r_{\mathrm{e}}$ (see Fig. 5), a parameter that can be measured by satellites (Nakajima and King, 1990). Freud et al. (2011) explain this methodology in more detail.

Based on this physical description, $N_{\mathrm{a}}$ is the most fundamental microphysical property of a convective cloud. It determines the rate at which the droplets grow with cloud depth in the updraft and in turn the rate at which they are converted into precipitation-sized particles. $N_{\mathrm{a}}$ also affects the radiative properties of the clouds, as higher concentrations reduce the droplet sizes for a given amount of cloud water (Twomey, 1977). $N_{\mathrm{a}}$ reflects not only $\mathrm{CCN}(S)$, but also the updraft velocities, as manifested in the actual supersaturation that these $\mathrm{CCN}$ were exposed to. However, direct 


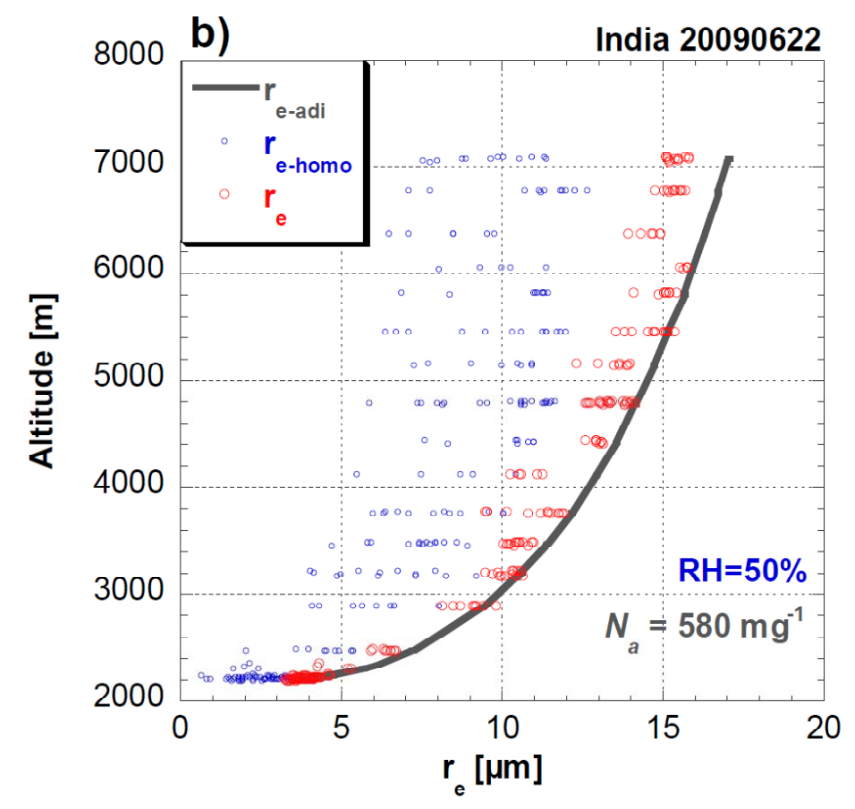

Fig. 2. Aircraft observations of tight relationships between $r_{\mathrm{e}}$ and altitude in a cluster of deep convective clouds over India. Each red circle marks the $r_{\mathrm{e}}$ measured in a 1-s $(\sim 100 \mathrm{~m})$ flight path. The dark curve shows the profile of the adiabatic $r_{\mathrm{e}}\left(r_{\mathrm{ea}}\right)$. The figure is taken from Freud et al. (2011), The $N_{\mathrm{a}}$ is calculated by the methodology described in Freud et al. (2011). It can be seen that for any given cloud depth the scatter of $r_{\mathrm{e}}$ is fairly small, and that values are normally within $2 \mu \mathrm{m}$ from $r_{\mathrm{ea}}$, despite including measurements with down to $5 \%$ of adiabatic water. The blue circles indicate the expected effective radii in case of fully homogeneous mixing with entrained air which has $50 \%$ relative humidity (RH), which was obtained from a nearby sounding. They are calculated for the mixing proportions of the actually measured adiabatic fractions. Similar relations are shown elsewhere in the world by Rosenfeld and Freud (2012).

measurement of $N_{\mathrm{a}}$ is usually not possible because entrainment of sub-saturated ambient air into the cloud decreases the cloud droplet concentrations by evaporation and dilution. Even the cores of deep convective clouds, where aircraft measurements are normally avoided due to the strong vertical motions and icing hazards, are prone to entrainment. This is mainly because of the fairly small horizontal extent and the strong turbulence in and near the convective cloud towers.

\section{$4 \quad N_{\mathrm{a}}$ controls the height for the onset of warm rain}

The droplet condensational growth is determined by the number of activated $\mathrm{CCN}\left(N_{\mathrm{a}}\right)$ and the height above cloud base, $D$. When the droplet effective radius $\left(r_{\mathrm{e}}\right)$ exceeds $\sim 14 \mu \mathrm{m}$, considerable precipitation mass is likely to form in growing convective clouds regardless of the extent of entrainment and mixing. This is because the low droplet concentrations and liquid water content in the diluted parts of the cloud, which slow the coalescence rate, are compensated by

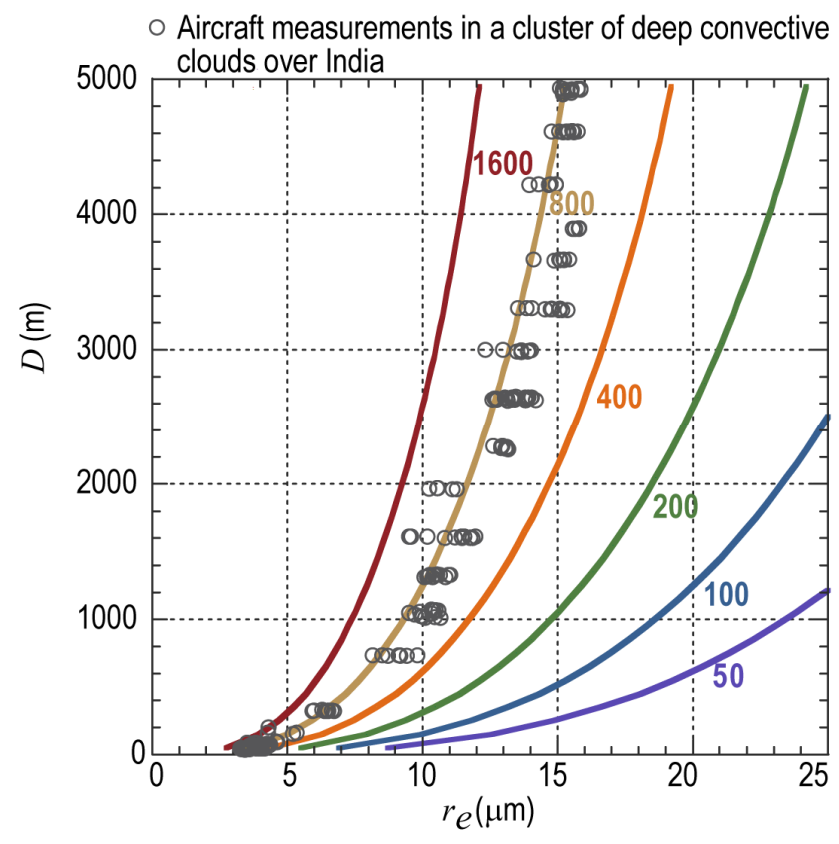

Fig. 3. Relationship between $r_{\mathrm{e}}$ and $D$ for various values of $N_{\mathrm{a}}$ in $\mathrm{cm}^{-3}$. The value derived from the profile of $r_{\mathrm{e}}$ measured by the aircraft is $N_{\mathrm{a}}=610 \mathrm{~cm}^{-3}\left(580 \mathrm{mg}^{-1}\right)$, within $5 \%$ of the directly aircraft-measured maximum cloud base droplet concentration.

the extra time and potential spectrum broadening due to typically weaker updrafts and preferred (partial) evaporation of the smaller droplets upon mixing in drier air. Additionally, the rate of droplet coalescence is proportional to $\sim \mathrm{r}_{\mathrm{e}}^{5}$ (Freud and Rosenfeld, 2012), which practically implies the existence of a threshold $r_{\mathrm{e}}$ above which efficient warm rain formation can occur. This threshold is reached at a known height above cloud base with a given $\mathrm{Na}$, because the vertical profile of $r_{\mathrm{e}}$ closely follows the theoretical adiabatic condensational growth curve, even in diluted clouds. The small observed deviations are mainly caused by deviations from purely inhomogeneous mixing which causes partial droplet evaporation. Consequently, the minimal cloud depth for precipitation formation $\left(D_{\mathrm{p}}\right)$ must theoretically change nearly linearly with $N_{\mathrm{a}}$ because the adiabatic water content increases nearly linearly with $D_{\mathrm{p}}$, with a slope that depends on the cloud base parameters. This means that in highly polluted clouds or where strong cloud-base updrafts occur (i.e., large $N_{\mathrm{a}}$ ), clouds may need to grow well above the freezing level, even in the tropical atmosphere, before precipitation forms either by warm or by mixed-phase processes. For full detail see Freud and Rosenfeld (2012). 


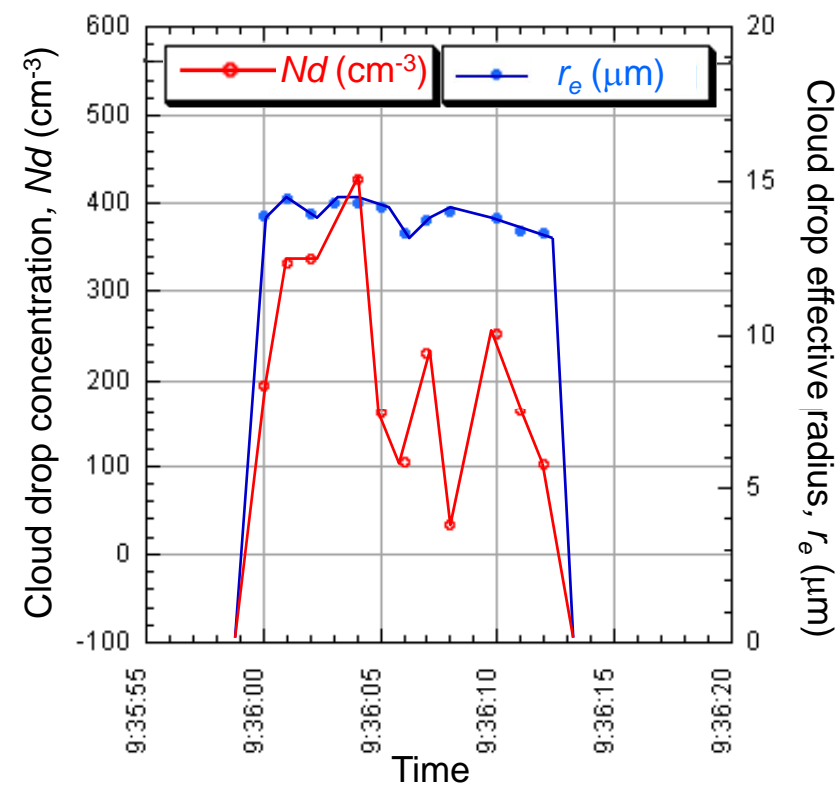

Fig. 4. The cloud drop concentration, $N_{\mathrm{d}}$, and effective radius, $r_{\mathrm{e}}$, at a horizontal cross section through a convective tower. Note the relative stability of $r_{\mathrm{e}}$ up to the cloud edge while $N_{\mathrm{d}}$ is highly variable. This is a manifestation of the nearly inhomogeneous mixing that dilutes $N_{\mathrm{d}}$ while keeping $r_{\mathrm{e}}$ nearly constant.

\section{Retrieving $N_{\mathrm{d}}$ from satellites}

Satellite retrieval of the column-integrated number of cloud droplets $\left[\mathrm{cm}^{-2}\right]$ is based on the retrieved vertical liquid water path (LWP). When LWP is given, the vertically averaged cloud droplet number density $N_{\mathrm{d}}$ can be estimated. Indirect measurements of $N_{\mathrm{a}}$ by satellite and lidar retrievals were previously applied to shallow marine stratiform clouds, with the main assumption that the clouds are composed of nearly adiabatic elements (Bennartz, 2007; Brenguier et al., 2000; Schuller et al., 2003; Snider et al., 2010). These retrievals had large uncertainties mainly due to violation of the adiabatic assumption and were not always validated with direct measurements. The retrieval of $N_{\mathrm{d}}$ worked well in several cases of extreme homogeneous marine stratocumulus, where these assumptions are closest to reality (Painemal and Zuidema, 2011). Furthermore, this methodology is not applicable to convective clouds due to their larger departure from the assumption that they are close to adiabatic as compared to marine startocumulus, and also due to the variable cloud top heights and depths at scales smaller than the typical satellite sensor resolution of $>1 \mathrm{~km}$.

The fact that $N_{\mathrm{d}}$ is vertically averaged and is subject to an unknown extent of dilution with ambient air renders it to be related only loosely to $\mathrm{CCN}$. In contrast, $N_{\mathrm{a}}$ is the fundamental property representing the combined effects of $\mathrm{CCN}(S)$ and cloud base updraft velocity, $w_{\mathrm{b}}$, which in turn determine other cloud properties. Consequently, the objective of this study is to introduce a method by which satellite

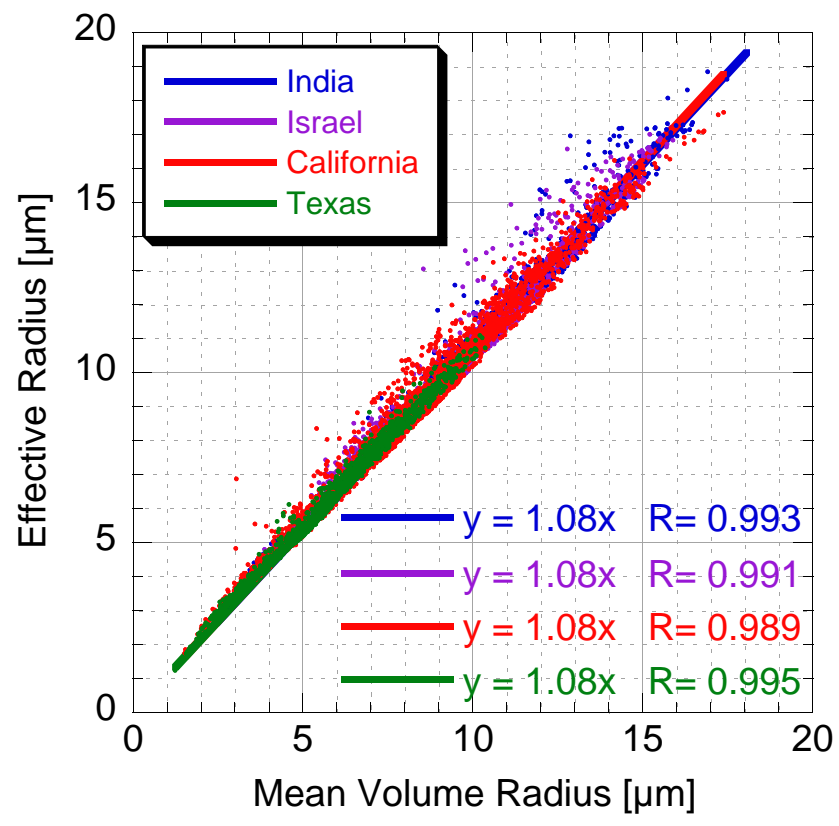

Fig. 5. The cloud droplet effective radius, $r_{\mathrm{e}}$, versus the droplet mean volume radius, $r_{\mathrm{V}}$, for $1 \mathrm{~Hz}$ averaged droplet size distributions measured for various locations, cloud types and by different cloud droplet probes. Note the universally highly repeatable and tight $r_{\mathrm{e}}-$ $r_{\mathrm{V}}$ relationship (from Freud and Rosenfeld, 2012).

observations of clouds can be used for retrieving $N_{\mathrm{a}}$ and its precursors, $\mathrm{CCN}(S)$ and $w_{\mathrm{b}}$.

\section{The scientific basis for retrieving $N_{\mathrm{a}}$}

Recent studies based on airborne measurements in deep convective clouds show that the cloud droplet effective radius $\left(r_{\mathrm{e}}\right)$ anywhere in the cloud is a strong function of the number of activated CCN $\left(N_{\mathrm{a}}\right)$ and the distance above cloud base (D) (Pawlowska et al., 2000; Andreae et al., 2004; Freud et al., 2008 and 2011; Freud and Rosenfeld, 2012; Rosenfeld et al., 2008b). The entrainment of sub-saturated air from the surroundings of the cloud and the mixing with the cloudy air, although reducing the cloud droplet concentrations and the liquid water content by evaporation and dilution, apparently does not have a strong effect on $r_{\mathrm{e}}$. The common explanation is that the mixing is strongly inhomogeneous, i.e., that the cloud droplets at the edges of a blob of entrained sub-saturated air quickly and completely evaporate while increasing the vapor content in the entrained air until it is saturated and cannot evaporate additional droplets. This lowers the droplet concentrations but leaves the shape of the droplet size spectra unchanged and hence does not affect $r_{\mathrm{e}}$. This is why if extreme inhomogeneous mixing is assumed and the cloud base properties are known, $N_{\mathrm{a}}$ can be derived from the vertical profile of $r_{\mathrm{e}}$ as long as the droplets grow mainly by condensation. When droplet coalescence is active and warm 
rain forms, then the unique relation between the vertical profile of $r_{\mathrm{e}}$ and $N_{\mathrm{a}}$ weakens. Therefore, the derivation of $N_{\mathrm{a}}$ is expected to be most accurate for $r_{\mathrm{e}}$ values smaller than $\sim 14 \mu \mathrm{m}$, where coalescence starts to dominate the cloud drop size distribution (Freud and Rosenfeld, 2012; Rosenfeld et al., 2012c). Errors in the measurements of $r_{\mathrm{e}}$ and departures from the extreme inhomogeneous assumption would affect the determination of $N_{\mathrm{a}}$, and therefore the effects of mixing would need to be accounted for.

Accurate measurements of $r_{\mathrm{e}}$ require vertical resolutions of the order of $100 \mathrm{~m}$. Moreover, accurate measurements of $r_{\mathrm{e}}$ as a function of the vertical distance above cloud base, $D$, require the minimization of 3-dimensional effects. The reduction of this effect can be accomplished by making measurements of $r_{\mathrm{e}}$ at wavelengths of about $3.7 \mu \mathrm{m}$, because the strong absorption of radiation by water at this wavelength reduces 3-dimensional effects (Rosenfeld et al., 2004; Painemal and Zuidema (2011). At shorter wavelengths where absorption is weaker (1.6 and $2.1 \mu \mathrm{m}$ ), a larger fraction of the light exiting a measured cloud pixel has been scattered by cloud particles inside and outside of the intended cloud measurement volume, thus degrading the accuracy of retrieved $r_{\mathrm{e}}$. Therefore, measurements at $3.7 \mu \mathrm{m}$ are inherently more accurate for retrieving $N_{\mathrm{a}}$ than measurements at 1.6 or $2.1 \mu \mathrm{m}$.

Taking into account the deviation from the extreme inhomogeneous mixing scenario when deriving $N_{\mathrm{a}}$ from the vertical profile of $r_{\mathrm{e}}$ is not straightforward. Freud et al. (2011) showed that with the inhomogeneous mixing assumption $N_{\mathrm{a}}$ was over-estimated on average by $\sim 30 \%$. This is because the measured $r_{\mathrm{e}}$ needs to be extrapolated to its adiabatic value (and converted to $r_{\mathrm{v}}$ ) before Eq. (1) can be applied. How much to add to the measured $r_{\mathrm{e}}$ depends mainly on the amount of entrainment and the relative humidity $(\mathrm{RH})$ of the entrained air. The RH may be estimated from the measurements of the absorption of the water vapor (in the 1120 $1150 \mathrm{~nm}$ band) near the edges of the clouds. It is proposed that the vertical profile of vapor near clouds will be retrieved by the derivative of the precipitable water as a function of height, when measured above the cloudy pixels at different heights in the cloud cluster of interest. The relative humidity will be calculated based on the known temperature as a function of height, as obtained from the measured temperatures of the reflecting reference cloud tops at the various heights. The accuracy of this method has not yet been determined, but it is expected to be much more accurate than the alternatives of forecast/reanalysis or derivation by satellite inversion techniques (e.g., Singh and Bhatia, 2006 and the references therein), because in this method the clouds serve as reflectors at known heights within the range of interest. Furthermore, the ability to calculate many vertical profiles for the same cloud around its sunlit side allows quantifying the local gradients and inhomogeneity of the moisture field.

Here, we retrieve $N_{\mathrm{a}}$ using the following algorithm:
1. Retrieve $r_{\mathrm{e}}(D)$, the vertical profile of $r_{\mathrm{e}}$, as a function of vertical distance above cloud base.

2. Convert the satellite retrieved $r_{\mathrm{e}}$ to $r_{\mathrm{v}}$ using the very tight and invariable linear relations between the two quantities, as shown in Fig. 2 here and more fully in Fig. 5 of Freud and Rosenfeld (2011).

3. Invoke the assumption of inhomogeneous mixing, which in the extreme condition means that $\mathrm{r}_{\mathrm{v}}$ equals $r_{\mathrm{va}}$, the adiabatic $r_{\mathrm{v}}$. This allows retrieving $N_{\mathrm{a}}$ in the following way:

$$
N_{\mathrm{a}}=3 /\left(4 q_{\mathrm{La}} \rho_{\mathrm{L}} \pi r_{\mathrm{va}}^{3}\right) \text {. }
$$

4. Correct $N_{\mathrm{a}}$ for the extent of homogeneous mixing and the resultant reduction of $r_{\mathrm{v}}$ with respect to $r_{\mathrm{va}}$. This correction is done based on the relative humidity near the cloud. This procedure will be tuned by analysis of already available aircraft measurements (Freud et al., 2011).

Instead of correcting for the extent of homogeneous mixing (step 4 above), it can be assumed that the highest $r_{\mathrm{e}}$ values from each level in the cloud (there will be a range of $r_{\mathrm{e}}$ values for each level because of the high resolution of the retrievals) represent the least diluted cloud elements, and therefore are closest to the adiabatic $r_{\mathrm{e}}$. Therefore, Eq. (1) may be used for deriving $N_{\mathrm{a}}$ (after replacing $r_{\mathrm{e}}$ with $r_{\mathrm{v}}$ ) from the fitting of the best $r_{\mathrm{e}}$ profile to the highest $r_{\mathrm{e}}$ values at each level. This profile would resemble the enveloping curve shown in Fig. 2 (dark grey line), which was calculated for an assumed $N_{\mathrm{a}}$. Charts like the one shown in Fig. 3 can be used for obtaining $N_{\mathrm{a}}$ when $r_{\mathrm{e}}(D)$ is retrieved. This way for deriving $N_{\mathrm{a}}$ does not require accounting for the mixing inhomogeneity, so it is quite simple and straight-forward. On the other hand it utilizes only a relatively small number of $r_{\mathrm{e}}$ values from each profile, and therefore may be more sensitive to noise in the data; the resultant $N_{\mathrm{a}}$ would be biased in the case that the utilized $r_{\mathrm{e}}$ values would be from cloud elements far from adiabatic.

The increase in $r_{\mathrm{e}}$ with cloud depth during the droplet condensational growth depends on $N_{\mathrm{a}}$ and the mixing ratio of the water vapor at cloud base. When $r_{\mathrm{e}}$ reaches $\sim 14 \mu \mathrm{m}$ in the convective clouds, warm rain starts to form (e.g., Rosenfeld, 1999 and 2000; Rosenfeld and Gutman, 1994; Gerber, 1996). As a result, if the cloud base temperature and pressure are known, the cloud depth at which $r_{\mathrm{e}}$ reaches the $14 \mu \mathrm{m}$ warm rain threshold $\left(D_{\mathrm{p}}\right)$ depends only on $N_{\mathrm{a}}$. However, since the mixing ratio of the adiabatic water increases nearly linearly with cloud depth, $N_{\mathrm{a}}$ and $D_{\mathrm{p}}$ should be linearly related for constant cloud base properties. Freud and Rosenfeld (2012) demonstrated this simple relationship with a small number of deep convective clouds over Israel and India. It would be interesting to see whether this relationship between $D_{\mathrm{p}}$ and $N_{\mathrm{a}}$ holds for a larger number of cases in different parts of the 
world based on the proposed methodology to derive $N_{\mathrm{a}}$ from space. If it holds, then it would be very useful to include this simple parameterization in coarse-resolution models that do not resolve single clouds.

The objective retrieval of $\mathrm{CCN}$ requires the ability to retrieve $r_{\mathrm{e}}$ accurately for the smallest possible fair weather boundary layer clouds and still resolve their vertical microstructure. The $r_{\mathrm{e}}$ is retrieved based on the observed extent of absorption of solar radiation in the clouds. Because $3.7 \mu \mathrm{m}$ radiation is absorbed in water 10 times more strongly than $2.2 \mu \mathrm{m}$ radiation, clouds are more opaque at $3.7 \mu \mathrm{m}$ and hence less affected by light arriving from outside of the measuring volume. The smallest practical size that can be used with little interference from adjacent cloud volume at $3.7 \mu \mathrm{m}$ is about $100 \mathrm{~m}$ (Rosenfeld et al., 2004). Taking into account the 3-D effects that are inherent to such small convective clouds allows the retrieval of $r_{\mathrm{e}}$ in convective clouds to an accuracy of $1 \mu \mathrm{m}$ (Zinner et al., 2008). An error of a factor $e$ in the retrieved $r_{\mathrm{e}}$ would be amplified by $e^{3}$ in the calculated $N_{\mathrm{a}}$. This means that an overestimate error of $1 \mu \mathrm{m}$ for a cloud with $r_{\mathrm{e}}=15 \mu \mathrm{m}$ would propagate to a bias error in $N_{\mathrm{a}}$ of $(16 / 15)^{3}=1.21$. This is a manageable uncertainty.

\section{The scientific basis for obtaining the updraft velocity near cloud base}

Cloud vertical motions can be obtained in principle by using a sequence of stereoscopic images that map the evolution of the cloud surface. The Multi Angle Imager (MAI) onboard CHASER has this capability. Two stereoscopic views $1 \mathrm{~min}$ apart can in principle provide the vertical component of the cloud surface evolution, by tracking protuberances at the cloud envelope. Tracking such protuberances near cloud base with an oblique view from the side can provide the vertical motion of these features, which approximates the mean updraft at cloud base. An illustration of such cloud features is given in Fig. 6. The challenge here is separating the observed movement into horizontal and vertical components. This can be assisted by the independent knowledge of the height for the central view of the cloud surface. This height can be obtained from the cloud temperature as measured by the MSI that is aligned with the center camera of the MAI. The cloud surface temperature can be uniquely related to cloud surface height in convective clouds, when using the moist adiabatic lapse rate and the cloud base temperature. Systematic bias errors in the height-temperature relations in the same cloud cluster would not affect the accuracy of the retrieval, and the vertical lapse rate is rather constant, as determined by known thermodynamic factors that do not vary much within the domain.

The cloud base updraft is highly correlated to the cloud top rate of rising above it (Blyth et al., 2005). Aircraft measurements show that the cloud top rising rate is on average half of the peak updraft within the cloud below the tops.

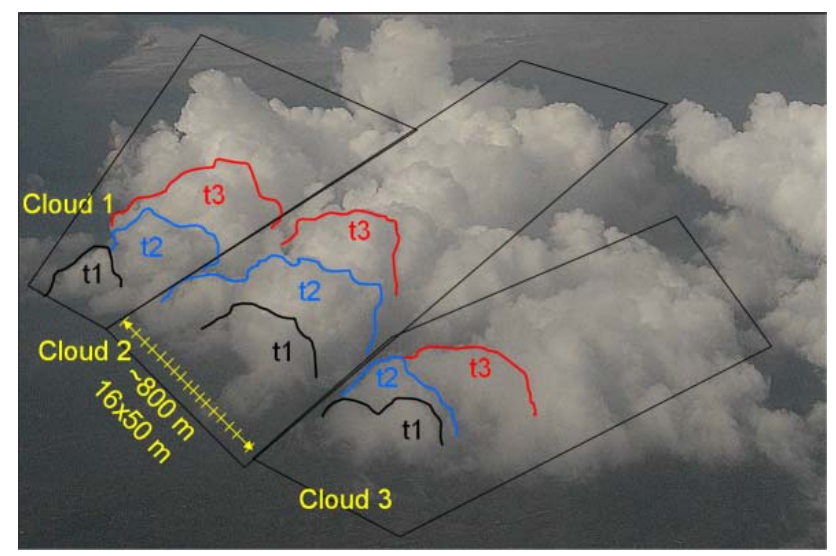

Fig. 6. Illustration of the topography of three small convective cloud segments. The contours show the possible development lines of the cloud top along three time steps, i.e., three views of the same cloud at $\mathrm{t} 1, \mathrm{t} 2$ and $\mathrm{t} 3$. These identifiable cloud features just above cloud base develop vertically at a similar rate as the cloud base updraft. The MAI $50 \mathrm{~m}$ resolution is illustrated at the scale bar. The resolution appears to be sufficient for mapping the marked perturbations and track these features along a sequence of three 1-min images, and map the average topographies for $\mathrm{t} 1$ to $\mathrm{t} 2$ and for $\mathrm{t} 2$ to $\mathrm{t} 3$. The differentiation of the two topographic maps will provide the cloud vertical motion. It appears that the retrieved updraft near cloud base, $w_{\mathrm{b}}$, would be the largest for cloud 1 and the smallest for cloud 3 .

The accuracy of the height retrieval by two Multi-angle Imaging SpectroRadiometer (MISR) cameras is about 300$500 \mathrm{~m}$ (Hovarth and Davis, 2001; Moroney et al., 2002). The MISR has a horizontal nadir resolution of $275 \mathrm{~m}$, versus the $50 \mathrm{~m}$ footprint of the MAI. This alone should reduce the error by a factor of 5 , resulting in an accuracy of $60-100 \mathrm{~m}$. The off nadir tilt of the MAI viewing geometry and the height reference provide additional significant improvement in the accuracy. This addresses the main source of inaccuracy, which is the uncertainty with respect to the separation of the observed cloud motion to vertical and horizontal components. The error of the motion of perfectly tracked cloud features is determined by uncertainty between the projections of the vertical and horizontal components of the cloud motion on the viewing angle from the satellite. Fixing one of the components allows the unambiguous determination of the other. This means that using a fixed reference height of a flat cloud base at the top of a well-mixed boundary layer for all three views can further improve substantially the accuracy with respect to the calculation above by at least a factor of about two, leading to an accuracy of about $50 \mathrm{~m}$.

Viewing the cloud at an angle of 30 degrees from the zenith allows the cloud bases to be measured, unless they are tilted towards the satellite by an angle that approaches 30 degrees. The tilt angle can be identified by the multiangle views. The determination of the cloud base in the central view is assisted by the cloud temperature. The warmest cloudy pixels represent temperature just above cloud base. 
We must have cloud base height and temperature for making a retrieval. Clouds have to be some distance apart in order to see the entire sides down to the cloud base. This distance can be computed by a simple geometrical calculation. One km deep clouds have to be at least $600 \mathrm{~m}$ apart for the retrieval to be possible. The cloud base and a piece of ground as its background, for a reference to the cloud base, needs to be observed.

The calculation of the supersaturation of the water vapor pressure near cloud base requires the determination of the updraft speed at cloud base $\left(w_{\mathrm{b}}\right)$. It is assumed that the vertical speed of cloud protuberances near cloud base is approximately equal to the updraft speed. The challenge is to separate the horizontal and the vertical components of the motion. This is accomplished by the procedure described next.

In order to separate the vertical and horizontal components, it is necessary to assume something as being fixed. In the situation of a well-mixed boundary layer from which convective clouds develop, the base of the clouds is flat at the convective condensation level, as determined by thermodynamic considerations. This height varies at a negligible rate compared to the vertical motions within the clouds. Therefore, cloud surface elements that are close to the base can be assumed to have the same horizontal motion as the cloud base. Under such an assumption, all the relative angular displacement of the cloud surface with respect to the cloud base can be ascribed to the vertical dimension. The mean horizontal wind has to be taken into account from the average motion of cloud bases.

In more general terms, the base of convective clouds is flat and at constant height. This provides a fixed reference for the MAI's three views of a single cloud and allows the horizontal motion at cloud base to be determined. The knowledge of the horizontal motion at the cloud base allows the separation of the horizontal and vertical components of the motion of cloud protuberances measured by MAI.

The accuracy of the vertical speed retrieval is approximately equal to the vertical motion of one pixel of $\Delta z=50 \mathrm{~m}$ between measurements $\Delta t=60 \mathrm{~s}$ apart, resulting in $\Delta z / \Delta t=0.8 \mathrm{~m} \mathrm{~s}^{-1}$. Tracking at least 10 pixels of a single protuberance increases the accuracy of the calculation to $\sim 0.2 \mathrm{~m} \mathrm{~s}^{-1}$. This provides measurements with the necessary accuracy for calculating $S$ even in marine stratocumulus clouds. However, a more cautious estimate of $0.5 \mathrm{~m} \mathrm{~s}^{-1}$ would still provide useful data for marine stratocumulus and will certainly suffice for other kinds of convective clouds.

\section{Combining $N_{\mathrm{a}}$ and $W_{\mathrm{b}}$ for obtaining the CCN spectra}

Earlier researchers used CCN spectra extensively because they can be obtained directly from in situ measurements with cloud chambers with control on varying the supersaturation. Often, these $\mathrm{CCN}$ spectra were parameterized using a power law of the form $\operatorname{CCN}(S)=\operatorname{CCN}(1 \%) \times S^{b}$, such that the spectra could be represented by a CCN concentration normalized to $S=1 \%$, and an exponent $b$. More recent studies have moved away from this approach for two reasons. First, it was found that the power law was often a poor approximation for the observed CCN spectra, and therefore, $b$ values could not be reliably associated with specific aerosol types (Gunthe et al., 2009; Rose et al., 2010). The second and more important reason is that this representation treats $\mathrm{CCN}$ as a "black box" by using a parameterization that does not contain any fundamental physical properties, and thus it is not amenable to prognostic modeling.

Current $\mathrm{CCN}$ research shows that the activation of an aerosol particle at a specific $S$ is predominantly determined by the number of water-soluble molecules or ions that it contains. The number of soluble molecules or ions, in turn, depends on the aerosol volume and composition (the number of soluble molecules per unit volume). The volume of the aerosol particle is specified by its dry diameter while the composition is specified by the hygroscopicity parameter, $\kappa$ (Petters and Kreidenweis, 2007). In this approach, the CCN properties of aerosols can be related directly to their basic physical and chemical properties, and therefore are amenable to prognostic modeling. State-of-the-art in situ measurements are based on size selection of aerosol particles followed by their activation to $\mathrm{CCN}$ in a cloud chamber, so that the dependence of activation on size and composition can be studied separately (Rose et al., 2008; Su et al., 2010).

These data are most beneficial for improving our understanding of how aerosols affect climate if they are used to test and improve the prognostic aerosol models that are incorporated into climate models. For this purpose, the $\mathrm{CCN}(S)$ spectra obtained from the CHASER measurements of the concentration of activated $\mathrm{CCN}$ as a function of the water vapor supersaturation, $N_{\mathrm{a}}(S)$, are considered to represent the $\mathrm{CCN}$ concentrations as a function of particle size $(d)$ and composition (Reutter et al., 2009). Figure 7 illustrates the relation between $S$ and $N_{\mathrm{a}}$ calculated as a function of the updraft speed near the cloud base $\left(w_{\mathrm{b}}\right)$, which can be described by Eq. (2):

$S=3.78 w_{\mathrm{b}}^{0.64} N_{\mathrm{a}}^{-0.4}$.

These calculations indicate that overestimates of $20 \%$ in $N_{\mathrm{a}}$ cause $S$ to be underestimated by $7 \%$, whereas overestimates of $20 \%$ in $w_{\mathrm{b}}$ cause $S$ to be overestimated by $12 \%$. Since the error of the estimates of $N_{\mathrm{a}}$ and $w_{\mathrm{b}}$ is $\sim 10 \%$ to $20 \%$, the error in the calculation of $S$ is $\sim 10 \%$.

Since aerosol particle size and composition affect CCN activation and can vary independently of one another, there is no unique way to convert a $\operatorname{CCN}(S)$ spectrum into a $\operatorname{CCN}(d, S)$ spectrum that would allow the retrieval of the desired functions $N_{\mathrm{a}}(d)$ and $\kappa(d)$. That is, the particle number concentration and hygroscopicity cannot be retrieved as a function of size without additional assumptions. Fortunately, recent research has yielded considerable information about $\kappa$ from both theoretical studies and laboratory and field 


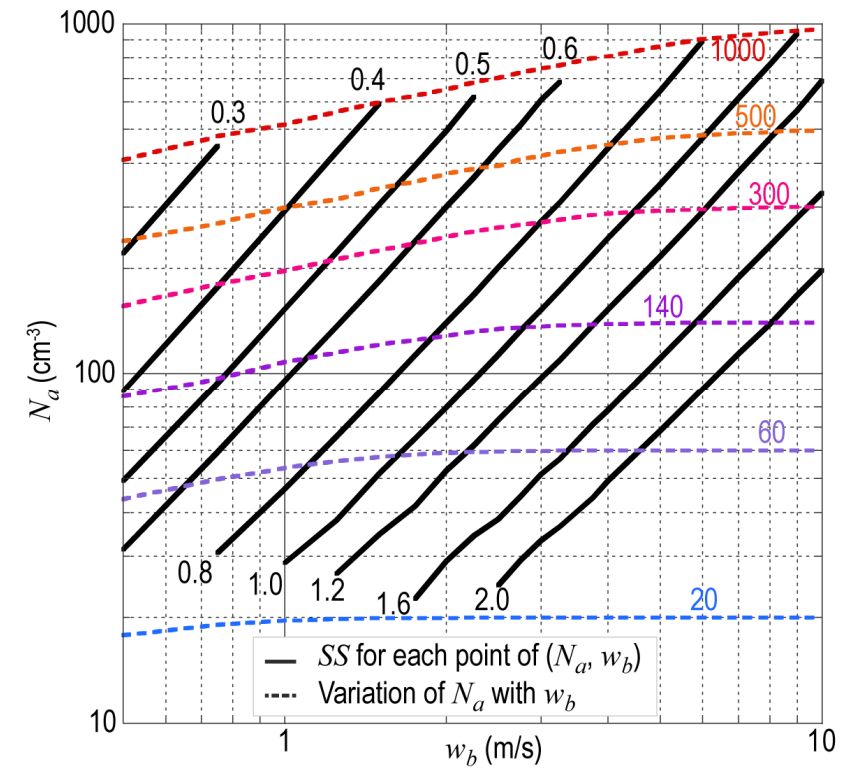

Fig. 7. The CCN spectra can be calculated using measurements or model simulations of $N_{\mathrm{a}}$ and $S\left(w_{\mathrm{b}}\right)$. This chart was drawn using data from Pöschl et al. (2010) for the activation of organic aerosol particles with $\kappa=0.13$ as observed for pristine tropical rainforest air. $\kappa=0.3$ is more representative for most other continental aerosol regimes. Increasing $\kappa$ would lower the $S$ values in the figure (Reutter et al., 2009).

measurements. This research shows that submicron aerosols, which constitute essentially almost all $\mathrm{CCN}$, can usually be represented as linear mixtures of an organic component with $\kappa \approx 0.1$ to 0.2 and an inorganic component with $\kappa \approx 0.6$ (Gunthe et al., 2009; Rose et al., 2011). Where appropriate, an additional sea salt component with a $\kappa \approx 1.3$ can be introduced. This approach has provided a global model of $\kappa$ distributions that is in very good agreement with observations (Pringle et al., 2010). A comparison with observations shows that modeled and observed $\kappa$ agree to $\leq 0.05$ for 10 out of 14 stations. Field campaigns have also shown that $\kappa$ does not usually change strongly with size over the range relevant to $\mathrm{CCN}$ active in convective clouds $(0.05-0.5 \mu \mathrm{m})$.

Once $\kappa$ is known or assumed, the distribution $\operatorname{CCN}(S)$ can be inverted to a distribution $\mathrm{CCN}(d)$ because for each $\kappa$ there is a functional relationship between the supersaturation and the critical particle diameter above which particles can be activated to cloud droplets. Thus, each supersaturation step in the $\mathrm{CCN}(S)$ spectrum corresponds to a size step in the $\mathrm{CCN}(d)$ spectrum, and the difference in $\mathrm{CCN}$ number concentration between the supersaturation steps yields the number of $\mathrm{CCN}$ in the corresponding size interval ( $\mathrm{Su}$ et al., 2010). An alternative approach would be to apply a model that predicts both aerosol size distribution and $\kappa$ on the basis of on aerosol source/sink and transport processes, such as the Global Model of Aerosol Processes (GLOMAP) (Spracklen et al., 2005a, 2005b, 2010). Although the size dis- tributions have larger errors associated with them than $\kappa$ has, both can be used as priors with specified weights and uncertainties, and an optimal $\kappa$ and $\mathrm{CCN}(d)$ can be derived from the $\mathrm{CCN}(S)$ spectrum.

\section{Error calculations and their propagation}

\subsection{Retrieving errors in cloud drop effective radius}

The sensitivity of the retrievals of $r_{\mathrm{e}}$ was tested for this study, using the MODIS Airborne Simulator aircraft data near the southern tip of Florida on 28 July 2006, at a sensor zenith angle around $30^{\circ}$ eastward of nadir, and solar zenith angle $35^{\circ}$ westward of zenith. The surface footprint at this geometry was near $70 \mathrm{~m}$.

An error of $1^{\circ} \mathrm{K}$ overestimate in brightness temperature of $3.7 \mu \mathrm{m}$ incurs an error of $0.8 \mu \mathrm{m}$ underestimate in $r_{\mathrm{e}}$ for $r_{\mathrm{e}}=14 \mu \mathrm{m}$. According to Table 1 , an instrument measurement noise of NEDT of $0.2^{\circ} \mathrm{K}$ in the $3.7 \mu \mathrm{m}$ channel would translate to added noise in $r_{\mathrm{e}}$ of $0.16 \mu \mathrm{m}$.

The error becomes larger at greater $r_{\mathrm{e}}$ and less at smaller $r_{\mathrm{e}}$. An error of $1^{\circ} \mathrm{K}$ overestimate in brightness temperature of $10.7 \mu \mathrm{m}$ incurs an error of $0.4 \mu \mathrm{m}$ overestimate in $r_{\mathrm{e}}$ for $r_{\mathrm{e}}=14 \mu \mathrm{m}$. The error becomes slightly larger at smaller $r_{\mathrm{e}}$. According to Table 1, an instrument measurement noise of NEDT of $0.1^{\circ} \mathrm{K}$ in the $10.7 \mu \mathrm{m}$ channel would translate to added noise in $r_{\mathrm{e}}$ of $0.04 \mu \mathrm{m}$.

An error of a factor of 1.1 overestimating the precipitable water above low cloud tops at $20^{\circ} \mathrm{C}$ over Florida during summer conditions incurs an error of about $0.6 \mu \mathrm{m}$ underestimate in $r_{\mathrm{e}}$ for $r_{\mathrm{e}}=14 \mu \mathrm{m}$. The error increases slightly for larger $r_{\mathrm{e}}$.

The accuracy of retrieval of water vapor above clouds by differential absorption near $0.9 \mu \mathrm{m}$ was shown to be about $0.2 \mathrm{~mm}$ (Albert et al., 2001). The accuracy is expected to be much improved at the $1.2 \mu \mathrm{m}$ waveband due to the greater absorption of vapor at that range.

An overestimate error of $0.2 \mathrm{~mm}$ in the precipitable water was calculated to incur an underestimate error of about $0.5 \mu \mathrm{m}$ in $r_{\mathrm{e}}$ for $r_{\mathrm{e}}=14 \mu \mathrm{m}$. The error decreases for smaller $r_{\mathrm{e}}$. This is a rather large sensitivity. The retrieval of $r_{\mathrm{e}}$ at $2.1 \mu \mathrm{m}$ is free of errors incurred by temperature measurements and has $1 / 3$ of the $3.7 \mu \mathrm{m}$ error due to inaccuracies in precipitable water above cloud. While the retrieved errors of $r_{\mathrm{e}}$ at $2.2 \mu \mathrm{m}$ are generally higher due to the smaller dependence on intervening vapor and the lack of need to separate the solar and thermal components of the radiation, the greater absorption at 3.7 $\mu \mathrm{m}$ (Mitchel, 2002) minimize the 3dimensional effects in the convective cloud elements, thus improving the accuracy for small cloud elements and for small distances above cloud base. The solar reflectance of the same opaque cloud in the visible is calculated to be at $3.7 \mu \mathrm{m}$ half of the reflectance at $2.1 \mu \mathrm{m}$. The retrieved $r_{\mathrm{e}}$ at $3.7 \mu \mathrm{m}$ of the smallest resolvable cloud depth of $100 \mathrm{~m}$ with $r_{\mathrm{e}}$ of $7 \mu \mathrm{m}$, 
is negligibly affected from surface properties when its liquid water content exceeds $0.25 \mathrm{~g} \mathrm{~m}^{-3}$ (Rosenfeld et al., 2004). The required geometrical depth or water content of a cloud with similar $r_{\mathrm{e}}$ for having the same opacity at $2.1 \mu \mathrm{m}$ is more than double. Therefore, an effort is made here to retrieve $r_{\mathrm{e}}$ at both wavelengths and use them in combination. The way by which they will be combined requires additional study.

Taking into account the 3 -D effects in the $2.1 \mu \mathrm{m}$ waveband allows a retrieval accuracy of $1 \mu \mathrm{m}$ (Zinner et al., 2008). Using the $3.7 \mu \mathrm{m}$ waveband is likely to increase the accuracy. The quantification requires repeating the study of Zinner at al. (2008) in this waveband.

\subsection{Error propagation in the calculation of $\mathrm{CCN}(S, d)$}

Freud et al. (2011) have shown based on aircraft measurements of vertical profiles of $r_{\mathrm{e}}$ and $N_{\mathrm{d}}$ that the assumption of extreme inhomogeneous mixing results in systematic overestimate bias of $N_{\mathrm{a}}$ by a factor of about 1.3 , when the cloud environment is dry, with $\mathrm{RH}$ of about $50 \%$. Taking into account the actual RH in the vicinity of the cloud may allow decreasing this bias and its uncertainty, as the difference between homogeneous and inhomogeneous mixing vanishes as the environmental RH goes to $100 \%$.

As shown already in Section 6, an error of a factor $e$ in the retrieved $r_{\mathrm{e}}$ would be amplified by $e^{3}$ in the calculated $N_{\mathrm{a}}$. This means that an overestimate error of $1 \mu \mathrm{m}$ for a cloud with $r_{\mathrm{e}}=15 \mu \mathrm{m}$ would propagate to a bias error in $N_{\mathrm{a}}$ of $(16 / 15)^{3}=1.21$. When this uncertainty is added to a similar error of about $20 \%$ due to deviations from the assumed mixing model, the error in $N_{\mathrm{a}}$ grows to a factor of 1.45 .

The concentration of CCN can be obtained if the maximum vapor supersaturation at cloud base height, $S$, is known. This, in turn, can be obtained from cloud base updraft speed, which can be retrieved from very high-resolution $(50 \mathrm{~m})$ dual stereoscopic images at oblique view of 30 degrees off nadir for the center camera. Assuming that a cloud protuberance seen from the three angles can be perfectly matched and tracked over the $2 \mathrm{~min}$ (validation of this assumption requires further research) and using the benefit of knowledge that cloud base is flat over a well mixed boundary layer can yield vertical motions $w_{\mathrm{b}}$ near cloud base with an accuracy of $0.2-0.5 \mathrm{~m} \mathrm{~s}^{-1}$. According to Eq. (2), a bias error of $20 \%$ in $w_{\mathrm{b}}$ causes $S$ to be biased by $12 \%$ in the same direction. When the errors are combined in the same direction, a $45 \%$ bias error in $N_{\text {a }}$ causes $S$ to be biased by $14 \%$ in the opposite direction. This allows the retrieval of the $C C N(S)$ with an accuracy of $25 \%$.

In order to obtain $C C N(S, d)$, where $d$ is the aerosol particle diameter, the hygroscopicity growth parameter of the aerosol, $\kappa$, must be known. With state-of-the-art global atmospheric chemistry and transport models, the average deviation between predicted and measured $\kappa$ values and CCN concentrations can usually be kept below $\sim 30 \%$ (e.g., Pringle et al., 2010; Spracklen et al., 2011). An error of $30 \%$ in $\kappa$ leads to an error of only $10 \%$ in the critical particle diameter of CCN activation (Kreidenweis et al., 2009; Pöschl et al., 2009), and the actual influence of $\kappa$ on cloud droplet number is even smaller because of compensation effects between updraft velocity, aerosol hygroscopicity and water vapor supersaturation (Reutter et al., 2009). Field measurement data confirm that the prediction of CCN concentration depends much more strongly on the variability of aerosol particle concentration and size than on the variability of $\kappa$ (e.g., Gunthe et al., 2009; Rose et al., 2010, 2011). The accuracy of individual CCN retrievals will depend on the accuracy of the available aerosol measurement and modeling data, and will thus vary for different regions and atmospheric conditions. In any case, $\kappa$ is expected to be one of the least uncertain and least critical aerosol parameters.

\section{Using the retrieved $\mathrm{CCN}$ and cloud properties for disentangling thermodynamics from aerosol effects}

\subsection{Measurements of thermodynamic parameters that affect clouds}

Clouds are affected primarily by thermodynamical conditions which determine to a large extent where and when they form, their updraft speeds and vertical extent. Aerosols modulate the cloud properties by affecting the cloud drop sizes and ice nucleation process, and in turn the rate of conversion of cloud water to hydrometeor, glaciation, latent heat release and evaporation. This, in turn, affects the cloud dynamics and feeds back to the meteorology.

Retrieving the CCN was described in the previous sections. In addition, the thermodynamic phase (ice versus liquid water) of the clouds can be retrieved by the method described by Martins et al. (2011), using the 2.1 and $2.3 \mu \mathrm{m}$ wavebands. A number of parameters that are a manifestation of the cloud forcing can be measured by CHASER. Such parameters are:

1. The cloud vertical growth rate. This is a manifestation of the atmospheric instability and forcing. It can be obtained from the stereoscopic analysis of the MAI.

2. The sensible $\left(Q_{\mathrm{h}}\right)$ and latent $\left(Q_{\mathrm{e}}\right)$ surface heat fluxes. The magnitude of the ratio between these fluxes $(B=$ $Q_{\mathrm{h}} / Q_{\mathrm{e}}$ ) determines to a large extent the thermodynamic surface properties and cloud forcing. Over the ocean $B$ is of the order of 0.1 , whereas $B$ is 5-10 times larger over land. $B$ can be obtained from comparisons of the surface skin to surface air temperature, where the latter can be calculated using the dry adiabatic lapse rate extended from the cloud base to the surface. This lapse rate can be retrieved because cloud base height, temperature and the surface temperature can all be retrieved by CHASER. 
Table 2. Contrast in land-ocean behavior in moist convection.

\begin{tabular}{|c|c|c|}
\hline Phenomenon & Thermodynamic Explanation & Aerosol Explanation \\
\hline $\begin{array}{l}\text { "Warm rain" convection more } \\
\text { prevalent over ocean }\end{array}$ & $\begin{array}{l}\text { Reduced time for coalescence in } \\
\text { stronger continental updraft }\end{array}$ & Larger droplets over ocean \\
\hline $\begin{array}{l}\text { Lightning activity more prevalent } \\
\text { over land } \\
\text { mixed phase region }\end{array}$ & $\begin{array}{l}\text { Greater instability over land and } \\
\text { stronger cloud base updraft }\end{array}$ & Enhanced delivery of cloud water to \\
\hline Large hail more prevalent over land & $\begin{array}{l}\text { Stronger updraft and thinner warm rain } \\
\text { region over land }\end{array}$ & $\begin{array}{l}\text { Enhanced delivery of cloud water to } \\
\text { mixed phase region }\end{array}$ \\
\hline $\begin{array}{l}\text { Upper tropospheric cirrus more } \\
\text { prevalent over land }\end{array}$ & $\begin{array}{l}\text { More vigorous ice production in } \\
\text { stronger updraft over land }\end{array}$ & $\begin{array}{l}\text { Greater numbers of small ice particles } \\
\text { nucleated over land }\end{array}$ \\
\hline
\end{tabular}

3. Vertical profile of the temperature and moisture. These properties can be retrieved from the vertical profiles of cloud surface temperature and the precipitable water above cloud elements at various heights.

4. Vertical profile of horizontal winds. This can be obtained from tracking layer cloud elements with the MAI, elements which can confidently be assumed not to grow vertically very fast, at various heights.

The essence of the difference between the land and ocean surface is the change in the sensible heat fluxes, relative humidity and respective cloud base height, and the resultant cloud base updrafts and organization which in turn contribute to the difference between the maritime and continental clouds to an unknown extent. Having the measurements of both the aerosols and these thermodynamic properties, along with the relative humidity and cloud vertical motions aloft, will provide a dataset from which it will be possible to disentangle the effects of the aerosols from the other effects. The substantiation for this claim is provided in the next subsection, which addresses the roles of both thermodynamic and aerosols in affecting clouds in ways that are difficult to separate.

\subsection{The entangled roles of aerosols and meteorology in controlling clouds}

Contrasts in the behavior of moist convection between land and ocean have been increasingly well quantified on a global basis by satellite observations over the last twenty years, and are summarized in Table 2. Large hail (Williams et al., 2005), lightning activity (Christian et al., 2003) and upper level cirrus cloud (Kent et al., 1995) are all substantially more prevalent over land than over ocean. In contrast, the prevalence of warm rain showers, in which ice particles are absent, is found over oceans (Williams and Stanfill, 2002; Liu and Zipser, 2009).

The traditional physical explanations for these contrasts, also reported in Table 2, are generally based on thermodynamic differences between land and ocean, which in turn are linked to contrasts in the surface properties (Table 3) of crustal materials and liquid water. The stronger heating of the land surface is responsible for greater air-surface temperature contrast and greater instability there (Williams and Renno, 1993), and for the larger updrafts at both cloud base height (Williams and Stanfill, 2002) and at higher levels of deep convection (Jorgenson and LeMone, 1989). The relatively recent upsurge of interest and observational attention to atmospheric aerosol (Molinié and Pontikis, 1995; Rosenfeld and Woodley, 2003; Hicks et al., 2005) has led to alternative physical explanations for the land/ocean contrasts (Table 2) that depend on the regulation of cloud droplet size and compete with the thermodynamic explanations so strongly that the two effects are difficult to distinguish from each other (Williams et al., 2002; Williams and Stanfill, 2002). New satellite-based methods are needed to address both explanations.

The plausibility of two possible explanations is underscored by the firmly established contrast in cloud condensation nuclei concentrations between land and ocean that is found in many regions (Table 3). Oceanic air is often clean, while continental air is polluted in many areas (Hogan, 1977; Schaefer and Day, 1981). This difference (Table 2) is widely attributed to the prevalence of aerosol sources over land (by smoke from fire, air pollution, emissions from vegetation, and lofting of mineral dust and by volcanic eruptions), and the weaker aerosol sources over the sea. The general contrast in CCN concentrations between polluted and clean regions is an order of magnitude (Andreae, 2009). However, the land/ocean contrast in cloud base height is as certain as the contrast between mostly polluted land and clean ocean in CCN (Williams and Satori, 2004; Williams et al., 2005), while the cloud base height is entirely independent of CCN concentrations. The thickness of warm cloud (difference between freezing level height and cloud base height) is necessarily generally greater over ocean and favors coalescence and the removal of cloud water as warm rain. The thermodynamic effect of thicker warm cloud over oceans mimics the aerosol effect there of cleaner air, smaller $\mathrm{CCN}$ concentration, larger cloud droplets and increased coalescence. Over oceans, the surface sensible heat flux is smaller and so the cloud base updraft strength is smaller (Table 3), nucleating 
Table 3. Contrast in land-ocean physical and meteorological properties.

\begin{tabular}{|c|c|c|}
\hline Property & Land & Ocean \\
\hline Surface heat capacity & Small $\left(0.2-0.5 \mathrm{cal} \mathrm{g} \mathrm{m}^{-1}{ }^{\circ} \mathrm{C}^{-1}\right)$, immobile surface & Large $\left(1\right.$ cal g m $\left.{ }^{-1}{ }^{\circ} \mathrm{C}^{-1}\right)$, mobile surface \\
\hline Air-surface temp. contrast & large $\left(1-10^{\circ} \mathrm{C}\right)$ & Small $\left(\sim 1^{\circ} \mathrm{C}\right)$ \\
\hline Bowen ratio & Large $(0.2-1)$ & Small $(0.1)$ \\
\hline Boundary layer $\mathrm{CCN}$ & High in polluted regions $\left(>1000 \mathrm{~cm}^{-3}\right)$ & Low in clean regions $\left(\sim 100 \mathrm{~cm}^{-3}\right)$ \\
\hline Cloud base height & High $(1000-4000 \mathrm{~m})$ & Low $(500 \mathrm{~m})$ \\
\hline Thickness of "warm" cloud & Small $(0-3000 \mathrm{~m})$ & Large $(\sim 4000 \mathrm{~m})$ \\
\hline Cloud base updraft speed & $\operatorname{High}\left(\sim 5 \mathrm{~m} \mathrm{~s}^{-1}\right)$ & Small $\left(\sim 2 \mathrm{~m} \mathrm{~s}^{-1}\right)$ \\
\hline CAPE & Larger $\left(0-3000 \mathrm{j} \mathrm{kg}^{-1}\right)$ & Smaller $\left(0-2000 \mathrm{j} \mathrm{kg}^{-1}\right)$ \\
\hline Convective updraft speed & $\operatorname{High}\left(>10 \mathrm{~m} \mathrm{~s}^{-1}\right)$ & Low $\left(<10 \mathrm{~m} \mathrm{~s}^{-1}\right)$ \\
\hline
\end{tabular}

a smaller fraction of the aerosols into cloud droplets and allowing more time for coalescence, and again favoring warm rain (Table 2).

Considering now the other three phenomena in Table 2 lightning, large hail and upper tropospheric cirrus clouds all three depend on the supply of condensate to the upper cloud. Lightning is mediated by graupel colliding with ice crystals. This graupel forms from supercooled water that has survived the coalescence process. Large hail forms by accretion of supercooled water in strong updrafts. Finally, upper tropospheric cirrus cloud depends on the nucleation of ice particles in the mixed phase region that is promoted by strong continental updrafts and by aerosol-rich air.

The disentanglement of thermodynamic and aerosol contributions to land/ocean contrasts in moist convection will require the simultaneous measurement of thermodynamic variables (CAPE, sensible heat flux, cloud base height, updraft speed) and the CCN at cloud base height, on the same set of clouds, comparing cloud properties over clean and polluted continental and marine regions. Then sensitivity analyses can be performed based on partial derivatives with respect to key thermodynamic and aerosol variables to quantify the various contributions.

Compelling evidence for a role for anthropogenic aerosol in the competition with thermodynamics in modifying moist convection is found in recent findings on the "weekend effect" (Bell et al., 2009; Rosenfeld and Bell, 2011), which are supported by the review of Sanchez-Lorenzo et al. (2012). In parallel with aerosol measurements showing a deficit concentration on weekends are findings that lightning, hail and tornadoes are all suppressed (by 10-20\%) over weekends relative to week days. In the absence of evidence for changes in thermodynamic quantities on the weekly time scale over continents, a distinct role for aerosol remains.

Thermodynamic explanations have been favored in explaining the dependence of lightning activity on island area (Williams et al., 2004), the semiannual variation of global lightning activity (Williams, 1994) and the interannual variation of lightning activity, both regionally (Hamid et al., 2001; Yoshida et al., 2007) and globally (Williams, 1992; Satori et al., 2009). Comprehensive studies of aerosol effects on lightning activity on the interannual time scale are lacking.

More recent efforts to distinguish thermodynamic from aerosol contributions in explaining local variations in oceanic lightning activity, arriving at the conclusion that aerosol effects are dominant, can be found in Yuan et al. (2011).

\section{Summary}

The scientific basis for a satellite mission to retrieve CCN concentrations and investigate their impacts on convective clouds is introduced here. It addresses the outstanding problem of cloud-mediated aerosol impacts on cloud radiative and thermodynamic forcing. The approach measures simultaneously the cloud composition and thermodynamic properties, and infers the number of activated $\mathrm{CCN}, N_{\mathrm{a}}$, from the vertical evolution of the retrieved cloud $r_{\mathrm{e}}$ in convective elements. The $N_{\mathrm{a}}$ can be retrieved with an accuracy of at least $45 \%$. To achieve this goal, multispectral measurements of the sun-illuminated side of the clouds at a resolution of $100 \mathrm{~m}$ are planned by the proposed CHASER satellite mission (Renno et al., 2012). The uncertainty in the model of mixing (homogeneous versus extreme inhomogeneous) can add another similar level of uncertainty, but this may be improved with assessment of the ambient relative humidity.

The concentration of CCN can be obtained if the maximum vapor supersaturation at cloud base height, $S$, is known. This, in turn, can be obtained from cloud base updraft speed, which can be retrieved from very high resolution $(50 \mathrm{~m})$ dual stereoscopic images at oblique view of 30 degrees off nadir for the center camera. The analysis with the benefit of knowledge that cloud base is flat over a well mixed boundary layer can yield vertical motions, $w_{\mathrm{b}}$, near cloud base with an accuracy of $0.2-0.5 \mathrm{~m} \mathrm{~s}^{-1}$. When the retrieval errors of $N_{\mathrm{a}}$ are combined in the same direction, a $45 \%$ bias error in $N_{\mathrm{a}}$ causes $S$ to be biased by $14 \%$ in the opposite direction. This allows the retrieval of the $\operatorname{CCN}(S)$ with an accuracy of $25 \%$.

In order to obtain $\operatorname{CCN}(S, d)$, where $d$ is the aerosol particle diameter, the hygroscopicity growth parameter of the aerosol $\kappa$ must be known. It can be obtained from emission 
sources and aerosol transport models with an accuracy of better than $30 \%$. For a given $\mathrm{CCN}(S)$, this allows the calculation of the size spectra of the CCN aerosols to an accuracy of better than $10 \%, C C N(d)$ is an essential aerosol property for simulating aerosol effects on cloud microstructure and precipitation forming processes. The estimates of accuracy should be refined based on simulations and validation against actual aircraft campaigns that simulate the satellite measurements and provide in situ validation of the cloud and $\mathrm{CCN}$ properties.

The aerosol properties are retrieved from the cloudy boundary layer, where other satellite-based methods of direct aerosol measurements are blind. This method is also free of problems that have plagued direct aerosol measurements, such as swelling of the particles at high RH, cloud contamination, and aerosols that are not at the same level as the cloud base.

Retrieving the vertical microstructure and thermodynamic properties of the clouds as well as the horizontal and vertical cloud motions allows obtaining simultaneous $\mathrm{CCN}$ concentrations, dynamics and thermodynamics of the clouds. This will make it possible to address effectively the outstanding challenge of disentangling meteorology from the aerosol effects on clouds, and hence the aerosol radiative and thermodynamic climate forcing. Section 9 introduces an approach for doing that.

In summary, the ability to retrieve simultaneously the cloud microphysical and thermodynamic properties and the aerosols in the underlying boundary layer will enable a major improvement in the accuracy of aerosol indirect radiative forcing and reduce substantially the magnitude of our uncertainty, which presently dominates the overall uncertainty in the magnitude of anthropogenic climate forcing.

Acknowledgements. The idea of retrieving $\mathrm{CCN}$ from space was stimulated by the discussions at the working group of remote sensing cloud-aerosol-precipitation-climate interactions, sponsored by the International Space Science Institute in Bern, Switzerland. We thank NASA Glenn Research Center, the University of Michigan, and DLR for supporting the development of the CHASER Mission concept. Many engineers, managers and technical staff played important roles on the development of CHASER. We also thank Vanderlei Martins, whose cloud side scanner inspired the development of the CHASER mission.

Edited by: A. Macke

\section{References}

Albert P., Bennartz, R., and Fischer, J.: Remote Sensing of Atmospheric Water Vapor from Backscattered Sunlight in cloudy Atmospheres, J. Atmos. Ocean. Tech., 18, 865-874, 2001.

Albrecht, B. A.: Aerosols, cloud microphysics and fractional cloudiness, Science, 245, 1227-1230, 1989.
Andreae, M. O., Rosenfeld, D., Artaxo P., Costa, A. A., Frank, G. P., Longo, K. M., and Silva-Dias, M. A. F.: Smoking rain clouds over the Amazon, Science, 303, 1337-1342, 2004.

Andreae, M. O., Jones, C. D., and Cox, P. M.: Strong present-day aerosol cooling implies a hot future, Nature, 435, 1187-1190, 2005.

Andreae, M. O.: Correlation between cloud condensation nuclei concentration and aerosol optical thickness in remote and polluted regions, Atmos. Chem. Phys., 9, 543-556, doi:10.5194/acp-9-543-2009, 2009.

Bell, T. L., Rosenfeld, D., Kim, K.-M., Yoo, J. M., Lee, M. I., and Hahnenberger, M.: Midweek increase in U.S. summer rain and storm heights suggests air pollution invigorates rainstorms, J. Geophys. Res., 113, D02209, doi:10.1029/2007JD008623, 2008.

Bell, T. L, Rosenfeld, D., and Kim, K.-M.: Weekly cycle in lightning: Evidence of storm invigoration by pollution, Geophys. Res. Lett., 36, L23805, doi:10.1029/2009GL040915, 2009.

Bennartz, R.: Global assessment of marine boundary layer cloud droplet umber concentration from satellite, J. Geophys. Res., 112, D02201, doi:10.1029/2006JD007547, 2007.

Blyth, A. M., Lasher-Trapp, S. G., and Cooper, W. A.: A study of thermals in cumulus clouds, Q. J. Roy. Meteorol. Soc., 131, 1171-1190, doi:10.1256/qj.03.180, 2005.

Brenguier, J. L., Pawlowska, H., Schuller, L., Preusker, R., Fischer, J., and Fouquart, Y.: Radiative properties of boundary layer clouds: Droplet effective radius versus number concentration, J. Atmos. Sci., 57, 803-821, 2000.

Burnet, F. and Brenguier, J. L.: Observational study of the entrainment-mixing process in warm convective clouds, J. Atmos. Sci., 64, 1995-2011, 2007.

Chen, T. C., Xue, L., Lebo, Z. J., Wang, H., Rasmussen, R. M., and Seinfeld, J. H.: A comprehensive numerical study of aerosolcloud-precipitation interactions in marine stratocumulus. Atmos. Chem. Phys., 11, 9749-9769, doi:10.5194/acp-11-9749-2011, 2011.

Christian, H. J., Blakeslee, R. J., Boccippio, D. J., Boeck, W. L., Buechler, D. E., Driscoll, K. T., Goodman, S. J., Hall, J. M. Koshak, W. J., Mach, D. M., and Stewart, M. F.: Global frequency and distribution of lightning as observed from space by the Optical Transient Detector, J. Geophys. Res., 108, 4005, doi:10.1029/2002JD002347, 2003.

Fan J., Yuan, T., Comstock, J. M., Ghan, S., Khain, A., Leung, R. L., Li, Z., Martins, V. J., and Ovchinnikov, M.: Dominant role by vertical wind shear in regulating aerosol effects on deep convective clouds, J. Geophys. Res., 114, D22206, doi:10.1029/2009JD012352, 2009.

Fan, J., Rosenfeld, D., Ding, Y., Leung, L. R., and Li, Z.: Potential aerosol indirect effects on atmospheric circulation and radiative forcing through deep convection. Geophys. Res. Lett., in press, doi:10.1029/2012GL051851, 2012.

Feingold, G., Yang, S., Hardesty, R. M., and Cotton, W. R.: Retrieving cloud condensation nucleus properties from Doppler cloud radar, microwave radiometer, and lidar, J. Atmos. Ocean. Tech., 15, 1189-1196, 1998.

Freud, E., Rosenfeld, D., Andreae, M. O., Costa, A. A., and Artaxo, P.: Robust relations between $\mathrm{CCN}$ and the vertical evolution of cloud drop size distribution in deep convective clouds, Atmos. Chem. Phys., 8, 1661-1675, doi:10.5194/acp-8-1661-2008, 2008. 
Freud E., Rosenfeld, D., and Kulkarni, J. R.: Resolving both entrainment-mixing and number of activated $\mathrm{CCN}$ in deep convective clouds. Atmos. Chem. Phys., 11, 12887-12900, doi:10.5194/acp-11-12887-2011, 2011.

Freud E. and Rosenfeld, D.: Linear relation between convective cloud drop number concentration and depth for rain initiation, J. Geophys. Res., 117, D02207, doi:10.1029/2011JD016457, 2012.

Gerber, H.: Microphysics of marine stratocumulus clouds with two drizzle modes, J. Atmos. Sci., 53, 1649-1662, 1996.

Goren, T. and Rosenfeld, D.: Observations of ship emission fully clouding broken marine stratocumulus over large areas, J. Geophys. Res., in review, 2012.

Gunn, R. and Phillips, B. B.: An experimental investigation of the effect of air pollution on the initiation of rain, J. Meteorol., 14, 272-280, 1957.

Gunthe, S. S., King, S. M., Rose, D., Chen, Q., Roldin, P., Farmer, D. K., Jimenez, J. L., Artaxo, P., Andreae, M. O., Martin, S. T., and Pöschl, U.: Cloud condensation nuclei in pristine tropical rainforest air of Amazonia: size-resolved measurements and modeling of atmospheric aerosol composition and CCN activity, Atmos. Chem. Phys., 9, 7551-7575, doi:10.5194/acp-9-75512009, 2009.

Hamid, E. F, Kawasaki, Z. I., and Mardiana, R.: Impact of the 199798 El Nino event on lightning activity over Indonesia, Geophys. Res. Lett., 28, 147-150, 2001.

Hicks, E., Pontikis, C. A., Nathou, N., and Asselin de Beauville, C.: Thunderstorms in the vicinity of the island of Guadeloupe as related to land-ocean contrast in lightning activity, Chapter 8 in Recent Progress in Lightning Physics, edited by: Pontikis, C., Research Signpost, Trivandrum, India, 2005.

Hogan, A.: Meteorological variation of maritime aerosols, in Atmospheric Aerosols and Nuclei, edited by: Roddy, A. F. and O’Connor, P. C., 503-507, Galway University Press, Ireland, 1977.

Horváth A. and Davies, R.: Feasibility and error analysis of cloud motion wind extraction from near-simultaneous multiangle MISR measurements, J. Atmos. Ocean. Technol., 18, 591608, 2001.

IPCC: Climate Change 2007 - The scientific basis. Contribution of working group I to the Fourth Assessment Report of the Intergovernmental Panel on Climate Change, Cambridge University Press, Cambridge, 2007.

Jiang, H., Feingold, G., and Koren, I.:Effect of aerosol on trade cumulus cloud morphology. J. Geophys. Res., 114, D11209, doi:10.1029/2009JD011750, 2009.

Jorgenson, D. P. and LeMone, M. A.: Vertical velocity characteristics of oceanic convection, J. Atmos. Sci., 46, 621-640, 1989.

Kent, G. S., Williams, E. R., Wang, P. H., McCormick, M. P., and Skeens, K. M.: Surface temperature-related variations in tropical cirrus clouds as measured by SAGE II, J. Climate, 8, 2577-2594, 1995.

Kiehl, J. T.: Twentieth century climate model response and climate sensitivity, Geophys. Res. Lett., 34, L22710, doi:10.1029/2007GL031383, 2007.

Koren, I., Remer, L. A., Kaufman, Y. J., Rudich, Y., and Martins, J. V.: On the twilight zone between clouds and aerosols, Geophys. Res. Lett., 34, L08805, doi:10.1029/2007GL029253, 2007.

Koren, I., Remer, L. A., Altaratz, O., Martins, J. V., and Davidi, A.: Aerosol-induced changes of convective cloud anvils produce strong climate warming, Atmos. Chem. Phys., 10, 5001-5010, doi:10.5194/acp-10-5001-2010, 2010.

Kreidenweis, S. M., Petters, M. D., and Chuang, P. Y.: Cloud particle precursors, in: Clouds in the perturbed climate system - their relationship to energy balance, atmospheric dynamics, and precipitation, edited by: Heintzenberg, J. and Charlson, R. J., MIT Press, Cambridge, 291-317, 2009.

Lebsock, M. D., Stephens, G. L., and Kummerow, C.: Multisensor satellite observations of aerosol effects on warm clouds, J. Geophys. Res., 113, D15205, doi:10.1029/2008JD009876, 2008.

Lehmann, K., Siebert, H., and Shaw, R. A.: Homogeneous and Inhomogeneous Mixing in Cumulus Clouds: Dependence on Local Turbulence Structure, J. Atmos. Sci., 66, 3641-3659, 2009.

Li, Z., Niu, F., Fan, J., Liu, Y., Rosenfeld, D., and Ding, Y.: Longterm impacts of aerosols on the vertical development of clouds and precipitation, Nature Geosci., doi:10.1038/ngeo1313, 2011.

Liu, C. and Zipser, E. J.: "Warm Rain" in the Tropics: Seasonal and regional distributions based on 9 years of TRMM data, J. Climate, 22, 767-779, 2009.

Martins, J. V., Marshak, A., Remer, L. A., Rosenfeld, D., Kaufman, Y. J., Fernandez-Borda, R., Koren, I., Correia, A. L., Zubko, V., and Artaxo, P.: Remote sensing the vertical profile of cloud droplet effective radius, thermodynamic phase, and temperature, Atmos. Chem. Phys., 11, 9485-9501, doi:10.5194/acp11-9485-2011, 2011.

Mitchel D. L.: Effective Diameter in Radiation Transfer: General Definition, Applications, and Limitations, J. Atmos. Scie., 59, 2330-2346, 2002.

Molinié, J. and Pontikis, C.: A climatological study of tropical thunderstorm clouds and lightning frequencies on the French Guyana Coast, Geophys. Res. Lett., 22, 1085-1088, 1995.

Moroney C., Davies, R., and Muller, J.-P.: Operational retrieval of cloudtop heights using MISR data, IEEE Trans. Geosci. Remote Sens., 40, 1532-1540, 2002.

Painemal, D. and Zuidema, P.: Assessment of MODIS cloud effective radius and optical thickness retrievals over the Southeast $\mathrm{Pa}$ cific with VOCALS-Rex in-situ measurements, J. Geophys. Res., 116, D24206, doi:10.1029/2011JD016155, 2011.

Paluch, I. R.: The entrainment mechanism in Colorado cumuli, J. Atmos. Sci., 36, 2467-2478, 1979.

Pawlowska, H., Brenguier, J. L., and Burnet, F.: Microphysical properties of stratocumulus clouds, Atmos. Res., 55, 15-33, 2000.

Penner, J. E., Xu, L., and Wang, M.: Satellite methods underestimate indirect climate forcing by aerosols, Proc. Nat. Acad. Sci., 108, 13404-13408, doi:10.1073/pnas.1018526108, 2011.

Petters, M. D. and Kreidenweis, S. M.: A single parameter representation of hygroscopic growth and cloud condensation nucleus activity, Atmos. Chem. Phys., 7, 1961-1971, doi:10.5194/acp-71961-2007, 2007.

Pinsky, M., and Khain, A. P.: Effects of in-cloud nucleation and turbulence on droplet spectrum formation in cumulus clouds, Q. J. Roy. Meteor. Soc., 128, 501-533, 2002.

Pöschl, U., Martin, S. T., Sinha, B., Chen, Q., Gunthe S. S., Huffman, J. A., Borrmann, S, Farmer, D. K., Garland, R. M., Helas, G., Jimenez, J. L., King, S. M., Manzi, A, Mikhailov, E., Pauliquevis, T., Petters, M. D., Prenni, A. J., Roldin, P., Rose, D., Schneider, J., Su, H., Zorn, S. R., Artaxo, P., and Andreae M. O.: Rainforest Aerosols as Biogenic Nuclei of Clouds and Precipita- 
tion in the Amazon, Science, 329, 1513-1516, 2010.

Pöschl, U., Rose, D., and Andreae M. O.: Climatologies of cloudrelated aerosols - Part 2: Particle hygroscopicity and cloud condensation nucleus activity, in: Clouds in the perturbed climate system - Their relationship to energy balance, atmospheric dynamics, and precipitation, edited by: Heintzenberg, J. and Charlson, R. J., MIT Press, Cambridge, 58-72, 2009.

Pringle, K. J., Tost, H., Pozzer, A., Pöschl, U., and Lelieveld, J.: Global distribution of the effective aerosol hygroscopicity parameter for $\mathrm{CCN}$ activation, Atmos. Chem. Phys., 10, 52415255, doi:10.5194/acp-10-5241-2010, 2010.

Quaas, J., Ming, Y., Menon, S., Takemura, T., Wang, M., Penner, J. E., Gettelman, A., Lohmann, U., Bellouin, N., Boucher, O., Sayer, A. M., Thomas, G. E., McComiskey, A., Feingold, G., Hoose, C., Kristj'ansson, J. E., Liu, X., Balkanski, Y., Donner, L. J., Ginoux, P. A., Stier, P., Grandey, B., Feichter, J., Sednev, I., Bauer, S. E., Koch, D., Grainger, R. G., Kirkevåg, A., Iversen, T., Seland, Ø., Easter, R., Ghan, S. J., Rasch, P. J., Morrison, H., Lamarque, J.-F., Iacono, M. J., Kinne, S., and Schulz, M.: Aerosol indirect effects - general circulation model intercomparison and evaluation with satellite data, Atmos. Chem. Phys., 9, 8697-8717, doi:10.5194/acp-9-8697-2009, 2009.

Renno, N. O., Williams, E., Rosenfeld, D., Fisher, D. G., Fischer, J., Kremic, T., Agrawal A., Andreae, M. O., Bierbaum, R., Blakeslee, R., Boerner, A., Bowles, N., Christian, H., Dunion, J., Horvath, A., Huang, X., Khain, A., Kinne, S., Lemos, M. C., Penner, J., Pöschl, U., Quaas, J., Seran, E., Stevens B., and Wagner T.: CHASER: An Innovative Mission Concept to Measure the Effects of Aerosols on Clouds and Climate. B. Am. Meteor. Soc., in review, 2012.

Reutter, P., Su, H., Trentmann, J., Simmel, M., Rose, D., Gunthe, S. S., Wernli, H., Andreae, M. O., and Pöschl, U.: Aerosol- and updraft-limited regimes of cloud droplet formation: influence of particle number, size and hygroscopicity on the activation of cloud condensation nuclei (CCN), Atmos. Chem. Phys., 9, 70677080, doi:10.5194/acp-9-7067-2009, 2009.

Rose, D., Nowak, A., Achtert, P., Wiedensohler, A., Hu, M., Shao, M., Zhang, Y., Andreae M. O., and Pöschl, U.: Cloud condensation nuclei in polluted air and biomass burning smoke near the mega-city Guangzhou, China - Part 1: Size-resolved measurements and implications for the modeling of aerosol particle hygroscopicity and CCN activity, Atmos. Chem. Phys., 10, 33653383, doi:10.5194/acp-10-3365-2010, 2010.

Rose, D., Gunthe, S. S., Su, H., Garland, R. M., Yang, H., Berghof, M., Cheng, Y. F., Wehner B., Achtert, P., Nowak, A., Wiedensohler A., Takegawa, N., Kondo, Y., Hu, M., Zhang, Y, Andreae, M. O. and Pöschl, U.: Cloud condensation nuclei in polluted air and biomass burning smoke near the mega-city Guangzhou, China - Part 2: Size-resolved aerosol chemical composition, diurnal cycles, and externally mixed weakly $\mathrm{CCN}$-active soot particles, Atmos. Chem. Phys., 11, 2817-2836, doi:10.5194/acp-112817-2011, 2011,

Rosenfeld, D.: TRMM observed _rst direct evidence of smoke from forest fires inhibiting rainfall, Geophys. Res. Lett., 26, 31053108, 1999.

Rosenfeld, D.: Suppression of rain and snow by urban and industrial air pollution, Science, 287, 1793-1796, 2000.

Rosenfeld, D. and Bell, T. L.: Why do tornados and hailstorms rest on weekends?, J. Geophys. Res., 116, D20211,
doi:10.1029/2011JD016214, 2011.

Rosenfeld, D. and Gutman, G.: Retrieving microphysical properties near the tops of potential rain clouds by multispectral analysis of AVHRR data, Atmos. Res., 34, 259-283, 1994.

Rosenfeld, D. and Lensky, I. M. : Satellite-based insights into precipitation formation processes in continental and maritime convective clouds, B. Am. Meteorol. Soc., 79, 2457-2476, 1998.

Rosenfeld, D. and Woodley, W. L.: Closing the 50-year circle: From cloud seeding to space and back to climate change through precipitation physics. Chap. 6, Cloud Systems, Hurricanes, and the Tropical Rainfall Measuring Mission (TRMM), edited by: Tao, W.-K. and Adler, R., Meteorol. Monogr., 51, 59-80, 2003.

Rosenfeld, D., Cattani, E., Melani, S., and Levizzani, V.: Considerations on daylight operation of $1.6 \mu \mathrm{m}$ vs $3.7 \mu \mathrm{m}$ channel on NOAA and METOP Satellites, B. Am. Meteorol. Soc., 85, 873881, 2004.

Rosenfeld, D., Kaufman, Y. J., and Koren, I.: Switching cloud cover and dynamical regimes from open to closed Benard cells in response to the suppression of precipitation by aerosols, Atmos. Chem. Phys., 6, 2503-2511, doi:10.5194/acp-6-2503-2006, 2006.

Rosenfeld, D., Lohmann, U., Raga, G. B., O’Dowd, C. D., Kulmala, M., Fuzzi, S., Reissell, A., and Andreae, M.O.: Flood or Drought: How Do Aerosols Affect Precipitation? Science, 321, 1309-1313, 2008a.

Rosenfeld, D., Woodley, W. L., Axisa, D., Freud, E., Hudson, J. G., Givati, A.: Aircraft measurements of the impacts of pollution aerosols on clouds and precipitation over the Sierra Nevada. J. Geophys. Res., 113, D15203, doi:10.1029/2007JD009544, 2008b.

Rosenfeld D., Donner, L. J., Wood, R., and Sherwood, S. C.: Uncertainties in aerosol cloud-mediated radiative forcing: two large and highly uncertain opposite effects from shallow and deep clouds. Position paper in the WCRP book on climate change, in review, Springer, available at: http://conference2011. wcrp-climate.org/documents/Rosenfeld_cloud_aerosol_V9.pdf, 2012a.

Rosenfeld, D., Woodley, W. L., Khain, A., Cotton, W. R., Carrió, G., Ginis, I., and Golden, J. H.: Aerosol effects on Intensity of Tropical Cyclones, B. Am. Meteor. Soc., 987-1001, 2012b.

Rosenfeld D., Wang H., and Rasch, P. J.: The roles of cloud drop effective radius and LWP in determining rain properties in marine stratocumulus, Geophys. Res. Lett., 39, L13801, 6 pp., doi:10.1029/2012GL052028, 2012c.

Sanchez-Lorenzo, A., Laux, P., Hendricks Franssen, H.-J., Calbó, J., Vogl, S., Georgoulias, A. K., and Quaas, J.: Assessing largescale weekly cycles in meteorological variables: a review, Atmos. Chem. Phys., 12, 5755-5771, doi:10.5194/acp-12-57552012, 2012.

Satori, G., Williams E., and Lemperger, I.: Variability of global lightning activity, Atmos. Res., 91, 500-507, 2009.

Schaefer, V. J. and Day, J. A.: A Field Guide to the Atmosphere, Houghton Mifflin Co., Boston, Mass., USA, 359 pp., 1981.

Schuller, L., Brenguier, J., and Pawlowska, H.: Retrieval of microphysical, geometrical, and radiative properties of marine stratocumulus from remote sensing, J. Geophys. Res., 108, 8631, doi:10.1029/2002JD002680, 2003.

Singh, D. and Bhatia, R. C.: Study of temperature and moisture profiles retrieved from microwave and hyperspectral infrared 
sounder data over Indian regions, Ind. J. Rad. Space Phys., 35, 286-292, 2006.

Snider, J. R., Leon, D., and Wang, Z.: Cloud droplet number concentration in VOCALS-REx, in: 13th Conference on Cloud Physics, Am. Meteorol. Soc., Portland, OR, USA, 2010.

Spracklen, D. V., Pringle, K. J., Carslaw, K. S., Chipperfield, M. P., and Mann, G. W.: A global off-line model of size-resolved aerosol microphysics: II. Identification of key uncertainties, Atmos. Chem. Phys., 5, 3233-3250, doi:10.5194/acp-5-3233-2005, 2005a.

Spracklen, D. V., Pringle, K. J., Carslaw, K. S., Chipperfield, M. P., and Mann, G. W.: A global off-line model of sizeresolved aerosol microphysics: I. Model development and prediction of aerosol properties, Atmos. Chem. Phys., 5, 22272252, doi:10.5194/acp-5-2227-2005, 2005b.

Spracklen, D. V., Carslaw, K. S., Pöschl, U., Rap, A., and Forster, P. M.: Global cloud condensation nuclei influenced by carbonaceous combustion aerosol, Atmos. Chem. Phys., 11, 9067-9087, doi:10.5194/acp-11-9067-2011, 2011.

Squires, P.: The microstructure and colloidal stability of warm clouds -1 : The relation between structure and stability, Tellus, 10, 256-261, 1958.

Su, H., Rose, D., Cheng, Y. F., Gunthe, S. S., Massling, A., Stock, M., Wiedensohler, A., Andreae, M. O., and Pöschl, U.: Hygroscopicity distribution concept for measurement data analysis and modeling of aerosol particle mixing state with regard to hygroscopic growth and CCN activation, Atmos. Chem. Phys., 10, 7489-7503, doi:10.5194/acp-10-7489-2010, 2010.

Twomey, S.: The influence of pollution on the short wave albedo of clouds, J. Atmos. Sci., 34, 1149-1152, 1977.

Wang, H., Rasch, P. J., and Feingold, G.: Manipulating marine stratocumulus cloud amount and albedo: a process-modelling study of aerosol-cloud-precipitation interactions in response to injection of cloud condensation nuclei, Atmos. Chem. Phys., 11, 4237-4249, doi:10.5194/acp-11-4237-2011, 2011.

Williams, E. R.: The Schumann resonance: A global tropical thermometer, Science, 256, 1184-1187, 1992.

Williams, E. R.: Global circuit response to seasonal variations in global surface air temperature, Mon. Weather Rev., 122, 19171929, 1994.
Williams, E. R. and Renno, N. O.: An analysis of the conditional instability of the tropical atmosphere, Mon. Weather Rev., 121, 21-36, 1993.

Williams, E. R. and Stanfill, S.: The physical origin of the landocean contrast in lightning activity, Compt. Rend.-Phys., 3, 1277-1292, 2002.

Williams, E. R, Rosenfeld, D., Madden, M., Gerlach, J., Gears, N., Atkinson, L., Dunnemann, N., Frostrom, G., Antonio, M., Biazon, B., Camargo, R., Franca, H., Gomes, A., Lima, M., Machado, R., Manhaes, S., Nachtigall, L., Piva, H., Quintiliano, W., Machado, L., Artaxo, P., Roberts, G., Renno, N., Blakeslee, R., Bailey, J., Boccippio, D., Betts, A., Wolff, D., Roy, B., Halverson, J., Rickenbach, T., Fuentes, J., and Avelino, E.: Contrasting convective regimes over the Amazon: Implications for cloud electrification. J. Geophys. Res., 107, 8082, doi:10.1029/2001JD000380, 2002.

Williams, E. R., Chan, T., and Boccippio, D.: Islands as miniature continents: Another look at the land-ocean lightning contrast. J. Geophys. Res., 109, D16206, doi:10.1029/2003JD003833, 2004.

Williams, E. R. and Sátori, G.: Lightning, thermodynamic and hydrological comparison of the two tropical continental chimneys. J. Atmos. Sol. Terr. Phys., 66, 1213-1231, 2004.

Williams, E. R., Mushtak, V. C., Rosenfeld, D., Goodman, S. J., and Boccippio, D. J.: Thermodynamic conditions favorable to superlative thunderstorm updraft, mixed phase microphysics and lightning flash rate, Atmos. Res., 76, 288-306, doi:10.1029/2001JD000380, 2005.

Wood, R.: Cancellation of aerosol indirect effects in marine stratocumulus through cloud thinning, J. Atmos. Sci., 64, 26572669, 2007.

Yuan, T., Remer, L. A., Pickering, K. E., and Yu, H.: Observational evidence of aerosol enhancement of lightning activity and convective invigoration, Geophys. Res. Lett., 38, L04701, doi:10.1029/2010GL046052, 2011.

Zinner, T., Marshak, A., Lang, S., Martins, J. V., and Mayer, B.: Remote sensing of cloud sides of deep convection: towards a three-dimensional retrieval of cloud particle size profiles, Atmos. Chem. Phys., 8, 4741-4757, doi:10.5194/acp-8-4741-2008, 2008. 